\title{
Slow-Nitrogen Releasing Urea-Coated Zinc and Magnesium Doped Hydroxyapatite Nanohybrids for the Wheat Crop Biofortification
}

\section{Bhaskar Sharma}

Deakin University

Manoj Shrivastava

Indian Agricultural Research Institute

Luis O. B. Afonso

Deakin University

\section{Udit Soni}

TERI School of Advanced Studies

David M. Cahill ( $\nabla$ david.cahill@deakin.edu.au )

Deakin University - Geelong Campus at Waurn Ponds https://orcid.org/0000-0002-2556-0528

\section{Research}

Keywords: Zinc and magnesium doped hydroxyapatite-urea nanohybrids, slow-release nitrogen, biofortification, nutrient delivery, urea release, doping, wheat crop growth and yield

Posted Date: October 1st, 2021

DOI: https://doi.org/10.21203/rs.3.rs-944725/v1

License: (c) (1) This work is licensed under a Creative Commons Attribution 4.0 International License.

Read Full License

Version of Record: A version of this preprint was published at ACS Applied Nano Materials on April 15th, 2022. See the published version at https://doi.org/10.1021/acsanm.2c01192. 


\section{Abstract}

Background: Chemical fertilizer is an indispensable component for optimal crop production in agriculture. However, excess urea fertilizer application to the agricultural fields leaves severe environmental deterioration. Researchers are actively seeking safer alternatives or solutions for the implementation of sustainable agriculture practices without compromising the agricultural output. Nano-scale particles, due to their unique properties, are emerging as interesting candidates for agrochemicals, especially nutrient delivery applications. In the present study, three variants hydroxyapatite-urea, magnesium-doped hydroxyapatite-urea, and zinc-doped hydroxyapatite-urea nanohybrids have been synthesized and characterized as slow nitrogen release fertilizers for the wheat crop.

Results: The doping of hydroxyapatite with zinc and magnesium instigated structural distortion that assisted relatively higher nitrogen loading and optimal urea release patterns. The nitrogen molecules slowly release from the water incubated nanohybrids, as per the Hixson-Crowell model equation, for up to two weeks in the soil environment. With zinc and magnesium integrated into hydroxyapatite, the synthesized nanohybrids now serve as a multi-nutrient complex of nitrogen, calcium, phosphorus, magnesium, and zinc nutrients. Additionally, iron uptake was increased in nanohybrids treated wheat crop. The results manifest the potency of the $50 \%$ nitrogen doses as nanohybrids that maintain the wheat crop yield and nutrient uptake equivalent to the $100 \%$ nitrogen doses as urea fertilizer. Higher nitrogen doses as nanohybrids significantly enhanced the wheat growth parameters. The zinc-doped hydroxyapatite-urea nanohybrids performed better among all three variants.

Conclusion: The research epitomized the delivery of multiple nutrients to the crops while mitigating ammonia emissions from agricultural fields. The doped and undoped hydroxyapatite-urea nanohybrids can be a revolutionary tool to alleviate the pollution and waste generation arising from agriculture. We present a comprehensive experimental evidence of the design and utilization of biocompatible nitrogen nanohybrids as fertilizer for agricultural production and biofortification while cutting off nitrogen input up to half to mitigate environmental repercussions. This study establishes extensive experimental evidence for manipulating nano-scale materials for nutrient delivery applications to crops and unlocks new paradigms for the design and application of climate-friendly smart fertilizers for sustainable agriculture.

\section{Background}

The world food demand is unceasingly rising for the growing population with an elevated standard of living, raising greater challenges to the agriculture and environment. The global population was rapidly surged to approximately seven-fold during the year 1850-2011 [1]. With the fastest population growth rate, Africa will be the major contributor (approximately 1.3 billion) to the world population by the year 2050 followed by Asia (approximately 0.9 billion) [2] where India and China are the prime contributors to the population ( $18 \%$ and $19 \%$, respectively) and food demand $(24.3 \%$ and $16.7 \%$, respectively) $[2,3]$. The global food demand may increase up to $62 \%$, and the population at risk of hunger may rise to $30 \%$ in the next three decades [4]. A recent study predicted steady growth in the global food demand and decreased 
crop production in the next three decades [5]. The contemporary pace of the agricultural output will not sustain to satisfy the future food demand, and therefore will need further advancements [6].

The use of fertilizers in agricultural land has dramatically surged during the past 50 years of the green revolution to enhance the agricultural output [7]. The use of excessive chemical fertilizer is one of the major reasons for improved crop output but at the cost of environmental pollution [8]. Unfortunately, the continuous application of chemical fertilizers reduces the soil nutrient capacity, soil friability, $\mathrm{pH}$, soil water holding capacity, and promote soil salinity, heavy metal accumulation, water eutrophication, nitrate accumulation, acid rain, the release of nitrogen and sulfur-containing gases that pollute the air and induce the greenhouse effect [9-11].

Urea is a popular source of nitrogen fertilizer and is one of the crucial constituents of chemical fertilizers, that are supplied to agricultural fields [12]. The crops consume only a small fraction of the total applied nitrogen nutrient throughout their life cycle, and a large amount of nitrogen is lost through either volatilization as ammonia or leaching as nitrate compounds [13]. Nitrous oxide and its derivatives are environment hazardous products of the nitrogen that release into the air from the agricultural fields [14]. As a result, the ammonia-nitrogen emission has surprisingly spiked approximately eight times over five decades between 1961 to 2010 [15]. The increased nitrogen application to the soil directly promotes nitrate accumulation in the soil that reaches the groundwater and contaminates the waterbodies [16]. There is a need to curtail the amount of chemical fertilizers, especially nitrogen fertilizer application into agricultural fields to mitigate the dangerous environmental consequences and health risks $[17,18]$.

On the other hand, the world's prevalence of undernourishment has improved between 2005 to 2017 due to technological improvements in agriculture, policy implementations, and wider employment programs [3]. Slow-release fertilizers and organic farming are among the fast-growing research areas for the establishment of safer alternatives to chemical fertilizers $[19,20]$. Nano-scale particles are another attractive and emerging candidate for nutrient delivery, due to their unique physical, chemical, optical, and electrical properties compared with bulk particles [21, 22]. Nanoparticles offer a larger surface area, flexible shape, smaller size, and rich surface chemistry for interaction with molecules for the delivery of the nutrient molecules to the plants [23]. The nutrient-loaded nanoparticles can be supplied to plants through either soil or leaf pores, depending on the size of the materials [24]. For example, nano-urea molecules were molecular structures that could be transferred to any plant or organism for nitrogen delivery [25]. Layered doubled hydroxide nanoparticles intercalated with phosphate ions could be termed as 'nano clay and used as a phosphorus fertilizer [26]. Several metal nanoparticles such as zinc, copper, and iron have already been tested for their potential as a micronutrient for plant growth and boosting immunity [27-29].

Hydroxyapatite is a widely available, biodegradable, and biocompatible compound that has been used for biomedical, and environmental applications [30-32]. Hydroxyapatite nanoparticles are crystalline and small structures made up of calcium and phosphorus in such a way that they may interact with a large number of substrate molecules and could be used as a nutrient carrier [33]. Hydroxyapatite nanoparticles 
have been investigated for their potential as a source of phosphorus fertilizer, and as a carrier for nitrogen nutrient delivery for agricultural applications but still, detailed research is needed for promising agricultural applications [34-36]. The efficient use for nutrient delivery and impact of the hydroxyapatite on different crop models are the most important aspects which require extensive research for their successful agricultural applications.

In this study, undoped hydroxyapatite-urea, magnesium doped hydroxyapatite-urea, and zinc doped hydroxyapatite-urea nanostructures were used as slow nitrogen releasing nano fertilizers for the delivery of the nitrogen nutrient to the plants. The different doses of the nitrogen nanohybrids were compared with the full nitrogen dose of the conventional urea fertilizer and investigated for the optimum crop growth and nutrient uptake

\section{Results}

\section{Characterization of urea loaded nanohybrids}

XRD patterns of the magnesium, and zinc doped, and undoped hydroxyapatite nanoparticles unveiled multiple peaks indicating polycrystalline nature with the highest intensity at (211) miller indices in the crystal lattice (Fig. 5.1) [37]. The presence of zinc and magnesium ions in the reaction medium readily replaces the calcium ions in the hydroxyapatite crystal lattice. The smaller ionic radius of the zinc $(0.074$ $\mathrm{nm})$ and magnesium $(0.072 \mathrm{~nm})$ ions allows the replacement with higher ionic radium calcium ion $(0.099$

$\mathrm{nm}$ ) altering the crystal structure of hydroxyapatite nanoparticles. The doping of hydroxyapatite with zinc and magnesium leads to the disfigurement of the hydroxyapatite crystal evidenced by lowered peak intensities and peak widening at (211) and (002) miller indices [33, 38, 39]. The doped nanostructures manifest crystal growth at a-axis and c-axis corresponding to $(200,002)$ planes that increased the surface area. The crystalline size of the largest peak (211) in the doped nanoparticles was contracted due to peak widening and increased FWHM induced by the replacement of calcium ions with zinc and magnesium. The urea-hydroxyapatite, urea-magnesium doped hydroxyapatite and urea-zinc doped hydroxyapatite nanohybrids exhibited urea phases observed with characteristics features peaks (110, $111,210)$ of urea. The interaction of urea with doped and undoped nanoparticles introduces a slight peak shift in the $(210,111)$ planes and structural modification due to weak interplay. The crystalline size of the peak (211) was $5.8 \mathrm{~nm}, 5.4 \mathrm{~nm}$, and $4.85 \mathrm{~nm}$ for HAP, MgHAP, and ZnHAP, respectively, and $42.2 \mathrm{~nm}$, $26.98 \mathrm{~nm}$, and $14.88 \mathrm{~nm}$ for $\mathrm{HAU}, \mathrm{MgHAU}$, and $\mathrm{ZnHAU}$, respectively.

The transmission electron microscopy of the synthesized nanohybrids showed morphological transformation upon urea capping (Fig. 5.2A-D). The hydroxyapatite nanoparticles showed an elongated rod-shaped crystalline structure with 20-25 nm width and 100-120 nm diameter (Fig. 5.2D). The hydroxyapatite nanoparticles are precipitated at a faster rate in the chemical reaction which gives rise to the unorganized, spindle-like structure. The hydrophilic surface of the spindle-like hydroxyapatite nanostructures forms thick and elongated clusters of numerous hydroxyapatite nanoparticles [37, 40, 41]. Interestingly, the rod-shaped and spindle-like structures of hydroxyapatite, upon addition of urea 
molecules, turns into unorganized globular or round-shaped structures with an approximate diameter of 120-130 nm (Fig. 5.2A). A higher surface area accommodates a large number of hydrophilic urea molecules that modify the overall shape of the nanohybrids. The average diameter of the urea-coated doped and undoped hydroxyapatite nanohybrids was increased compared with bare nanoparticles. The magnesium and zinc-doped hydroxyapatite-urea nanohybrids exhibited a relatively smaller diameter of about 75-100 nm than undoped hydroxyapatite-urea (Fig. 5.2B-C).

The scanning electron microscopy of the doped and undoped hydroxyapatite nanoparticles showed a morphological appearance with continuous small clusters of the unorganized rod-shaped molecules (Fig. 5.3A-F). The smaller spindle-shaped molecules were merged to produce uneven and irregular structures in magnesium and zinc-doped hydroxyapatite nanoparticles [40, 41]. Urea-coated hydroxyapatite nanoparticles formed a larger irregular-shaped structure. The urea phase association over the doped and undoped hydroxyapatite crystals was predicted through adsorption or weak interactions on the surface. The average diameter of the nanohybrids was observed to be less than $100 \mathrm{~nm}$.

The energy dispersive $\mathrm{X}$-ray analysis of the nanostructures confirms the presence of base hydroxyapatite matrix composed of oxygen, phosphorus, calcium in undoped and oxygen, phosphorus, calcium, zinc, and magnesium in the doped hydroxyapatite nanoparticles (Fig. 5.4A-D).

The characteristic functional groups of urea $(\mathrm{C}-\mathrm{N}, \mathrm{N}-\mathrm{H}, \mathrm{C}=\mathrm{O})$ and hydroxyapatite $\left(\mathrm{PO}_{4}{ }^{3-}, \mathrm{P}-\mathrm{O}, \mathrm{O}-\mathrm{P}-\mathrm{O}\right)$ were identified using FTIR (Fig. 5.5). A broad spectral peaks absorption of the O-P-O and $\mathrm{PO}_{4}{ }^{3-}$ functional groups in the magnesium and zinc doped hydroxyapatite nanoparticles was observed compared with undoped hydroxyapatite nanoparticles (Fig. 5.5A-C) [42]. The doping of the magnesium and zinc in the hydroxyapatite replaces calcium ions and affects the vibrational energies of the functional groups (Fig. 5.5B-C). The spectral changes were noticed due to the $\mathrm{v}_{4}$ vibrations of the O-P-O and $\mathrm{PO}_{4}{ }^{3-}$ functional groups. A common $\mathrm{v}_{1}$ symmetric $\mathrm{P}-\mathrm{O}$ mode stretching at $952-960 \mathrm{~cm}^{-1}$, and a weak $\mathrm{O}-\mathrm{H}$ stretching region at $3435-3450 \mathrm{~cm}^{-1}$ was noticed due to the presence of absorbed water in all the nanoparticles.

The interaction of the urea molecules on the surface of the hydroxyapatite nanoparticles was characterized by the spectral shifts in the $\mathrm{N}-\mathrm{H}, \mathrm{C}=\mathrm{O}$, and $\mathrm{C}-\mathrm{N}$ functional groups [43]. The ZnHAU and MgHAU were observed with $\mathrm{N}-\mathrm{H}$ peak $\left(1635-1645 \mathrm{~cm}^{-1}\right)$ shift and peak widening compared with urea $\left(1590 \mathrm{~cm}^{-1}\right)$ (Fig. 5.5B-C). Moreover, the spectral shift in the $\mathrm{C}=\mathrm{O}$ and $\mathrm{C}-\mathrm{N}$ regions of the ureananohybrids indicate the unstable chemical environment that arose during vibrations in dipole movements. The 0-P-O stretches of the bare nanoparticles were modified in the urea nanohybrids evidenced by spectral shifts under the influence of the weak interactions. The peak intensity of the phosphate site was decreased in all the urea nanohybrids compared with bare nanoparticles because of the site occupation by urea molecules. Weak interactions such as hydrogen bonds could promote interaction between urea and hydroxyapatite nanoparticles. The changing chemical environment in the 
urea nanohybrids was captured by the peak shifts in the functional groups of urea and hydroxyapatite nanoparticles.

The absorption spectra of the undoped nanohybrids show an absorption peak at $199 \mathrm{~nm}$ while the doped nanohybrids exhibit an absorption peak shift to a shorter wavelength (Fig. 5.6A) indicating possible electronic transitions induced by crystal deformation and bonding pattern [44]. The free-electron oscillation of the zinc and magnesium in the hydroxyapatite nanostructures leads to modify resonant wavelength and energy levels $[45,46]$. Therefore, the absorption peak shift in urea bound to doped nanoparticles was noticed compared with undoped nanoparticles and pure urea molecules.

The average particles size of the undoped hydroxyapatite nanoparticles was observed to be $406 \pm 66.9$ $\mathrm{nm}$ which was reduced for magnesium and zinc doped hydroxyapatite nanoparticles to $182.3 \pm 14.4 \mathrm{~nm}$ and $246.5 \pm 31.1 \mathrm{~nm}$, respectively (Fig. 5.6B). These results support the observations from XRD and TEM analysis and confirm that the size of the hydroxyapatite nanoparticles reduces after zinc and magnesium doping. The average hydrodynamic diameter of the urea-coated hydroxyapatite nanohybrids was around $721.8 \pm 83.7 \mathrm{~nm}$, while magnesium and zinc doped hydroxyapatite-urea nanohybrids were found to be $382.1 \pm 52.2$ and $472.9 \pm 45.9 \mathrm{~nm}$, respectively. The Zeta potential of the hydroxyapatite, magnesium, and zinc doped hydroxyapatite nanoparticles was $20.2 \mathrm{mV}, 24.9 \mathrm{mV}$, and $10.8 \mathrm{mV}$, respectively. The zeta potential of the nanoparticles was altered to $-5.1 \mathrm{mV},-14.8 \mathrm{mV}$, and $-9.3 \mathrm{mV}$ in the hydroxyapatite-urea, magnesium-doped hydroxyapatite-urea, and zinc-doped hydroxyapatite-urea, respectively after urea coating or adsorption. The zinc doping into hydroxyapatite decreased the zeta potential and induced rapid coagulation that may favor stronger interaction with urea molecules [47].

\section{Slow-release of urea molecules from nanohybrids}

Urea molecule release from nanohybrids was compared with the conventional nitrogen fertilizer (urea granules) in a soil matrix packed in a closed column. The $93 \%$ granular urea molecules were released from the soil within 30 minutes of incubation followed by a complete release in another six minutes. The soil microorganisms transform the nitrogen into ammoniacal-nitrogen and nitrate-nitrogen which plants often require for uptake $[48,49]$. The faster release of the urea causes rapid loss of nitrogen through either leaching or volatilization which leads to a higher amount of granular urea application to agricultural fields and environmental pollution [50-52].

Nitrogen and oxygen atoms of the urea molecules have unshared pairs of electrons that induce hydrogen bonding with either urea molecules or other molecules in the solvent to form molecular aggregates. The urea molecules often self-aggregate in the less polar solutions and the weak hydrogen bond-forming environment $[53,54]$. In the water environment, the enthalpy of the dissolution is lowest and entropy change is high [55]. The water molecules interact well with urea molecules and reduce urea aggregation while destroying the clusters of water molecules [53]. The enthalpy of the dissolution in the water was reported to be $15.39 \mathrm{~kJ} \mathrm{~mol}^{-1}$ estimated through the direct calorimetry method [56]. The differences in the hydrogen bond energies dissolve the urea molecules in water by fitting urea molecules into the hydrogen-bonded water [57]. The energy required to generate a cavity of about $3.2 \AA$ diameter is 
approximately $18 \mathrm{~kJ} \mathrm{~mol}^{-1}$ which is very close to the enthalpy of urea dissolution in water [58]. Therefore, the urea solute dissolution depends on the free energy change of dissolution in water and ease of cavity generation.

According to density functional theory, urea and water interaction causes instability of the urea dimers and induces dissociation in the abundance of water molecules [59]. The urea molecules dissociate rapidly in the presence of water and stay linked through water bridges. The urea granules release urea molecules rapidly in water due to interaction through myriad hydrogen bonds. The rapid dissolution of urea molecules in water causes a loss of a large amount of urea because water dissolved urea can leach away in groundwater and water bodies [60]. The aqueous urea solution in the soil matrix encounters soil urease from microorganisms that transform urea-nitrogen into ammoniacal-nitrogen intermediate and nitrogen is lost as ammonia gas [61]. In the experiment, urea molecules were released $99 \%$ within 36 minutes under a constant flow of water medium in the soil matrix.

HAU, MgHAU, ZnHAU nanohybrids released $13.61 \%, 13.65 \%, 15.10 \%$ urea molecules, respectively compared with $93 \%$ urea from granular urea within half an hour of incubation in a water environment. The release of urea molecules from nanohybrids was substantially turned down in comparison to granular urea. The higher surface area of the $\mathrm{Zn}$ and $\mathrm{Mg}$-doped and undoped nanoparticles allowed the interaction of a large number of urea molecules [62]. The interaction between urea molecules and nanoparticles changed the urea-free energy change of dissolution in the water [59]. The nanoparticles interfere with the cavity formation capabilities of the urea in the water environment that reduce its dissolution in water $[63,64]$. The surrounding cluster of water molecules now requires more energy to create a cavity to dissolve urea due to the presence of nanomaterials [65].

The experiment revealed that $69 \%$ urea molecules from $\mathrm{HAU}, 82 \%$ urea from $\mathrm{MgHAU}$, and $36.62 \%$ urea from $\mathrm{ZnHAU}$ were released within 120 minutes of incubation under a continuous flow of water. Interestingly, the maximum urea release was observed in the MgHAU among all the nanohybrids and $\mathrm{ZnHAU}$ nanohybrids showed a very slow release of urea. The substitution of zinc in the hydroxyapatite structures may induce the adhesion bond strength and distorted crystallinity which could accommodate more urea molecules than undoped hydroxyapatite with better adhesion $[66,67]$. Zinc substitution leads to a better substrate holding capacity until the energy of surrounding water molecules builds a cavity for urea dissolution [66]. In the nanohybrids, the surface hydroxyl ions and calcium ions on the hydroxyapatite nanoparticles may interact with urea molecules on either oxygen or hydrogen atoms through hydrogen bonds or electrostatic forces [68]. Therefore, the coating of urea molecules avoids direct contact of water with hydroxyapatite until sufficient urea is released over time.

The magnesium doped hydroxyapatite nanoparticles were reported to be not altering the adhesive bond strength [69] and therefore, MgHAU and HAU nanohybrids showed a substantial release of urea molecules compared with ZnHAU. In the results, MgHAU and ZnHAU changed the crystallinity of the undoped hydroxyapatite nanoparticles that could assist in the loading of a higher amount of urea on their surfaces [62]. The HAU, MgHAU, and ZnHAU released $80.38 \%, 88.27 \%$, and $71.57 \%$ urea molecules in 
seven days of incubation in comparison with $99.34 \%$ release of the granular urea. The nanohybrids are much capable of diminishing the burst release of urea in the soil environment. All the nanohybrids showed significant cutback of rapid urea release under the continuous flow of water in the soil matrix. The results substantiate the best performance by ZnHAU nanohybrids which still hold approximately $29 \%$ urea in the soil after seven days of water incubation. The remaining urea in the soil becomes available as a nitrogen source for a longer time for crops and reduces the nitrogen requirement.

Further, the urea release kinetics pattern of the urea fertilizer and nanohybrids were analyzed through linear curve-fitting on existing release models. The urea and nanohybrids release patterns were best fitted on a linear curve of the Hixson-Crowell model equation [70]. The dissolution of urea molecules occurred in planes parallel to the surface of dosage, which decreases proportionally over time [70]. The urea release was limited by the dissolution velocity than diffusion and the dimension of the nanohybrids or

urea granules gradually decreasing as urea molecules were disassociating and releasing in the water. The maximum $\mathrm{R}^{2}$ values were found to be 0.98 for all three nanohybrids $\mathrm{HAU}, \mathrm{MgHAU}$, and $\mathrm{ZnHAU}$. The dissolution velocity of the urea depends on the number of neighboring water molecules forming cavities. As the dissolution starts in the homogenous matrix, the size of the nanohybrids decreases due to the release of urea. The nanohybrids show multi-fold slow release of urea compared with urea granules and confirm the suitability for agricultural application $[71,72]$. The burst release of urea is often lost through leaching and volatilization of nitrogen [73-75]. The nanohybrids can be used to replace urea fertilizer to trim the nitrogen application to the agricultural field and avoid environmental pollution.

\subsubsection{Nanohybrids influence wheat crop growth}

The impact of the nitrogen-loaded nanohybrids hydroxyapatite-urea (35.72\% nitrogen), magnesium doped hydroxyapatite-urea ( $42.53 \%$ nitrogen), and zinc doped hydroxyapatite-urea ( $41.68 \%$ nitrogen) on the wheat crop growth and nitrogen availability was examined. Urea release pattern from the nanohybrids in the soil matrix ensures long-term availability of nitrogen for the plants. The slow nitrogen release behavior and biocompatibility of the nanohybrids could be exploited to reduce chemical fertilizer application to agricultural fields. Consequently, $50 \%, 75 \%$, and $100 \%$ doses of the recommended nitrogen as nanohybrids were used compared with $100 \%$ of the recommended nitrogen dose of conventional nitrogen fertilizer for the evaluation of wheat crop growth, and nutrients uptake. All the nitrogen fertilizers were applied in two doses, the first half at the time of sowing and the second half after 45 days of sowing.

The nitrogen supplied as nanohybrids significantly enhanced the agronomic traits of the wheat crop. A significant improvement in the plant height by $6.4 \%$ and $4.6 \%$ in the MgHAU-100 and ZnHAU-100 treatments, respectively, was observed compared with the control (Fig. 5.9A). Similarly, the effective tiller count was enhanced in all the $100 \%$ nitrogen as nanohybrid treatments and was maintained in all other nanohybrid treatments (Fig. 5.9B). The results suggest the sufficient availability of nitrogen for crop uptake at the early growth stage as the tillers formation is associated with plant growth and biomass accumulation [76-78]. There was no statistically significant change in the NDVI (Normalized Difference Vegetative Index) of the nano-fertilizer treated crops compared with control (Fig. 5.9C). The balanced 
NDVI measures indicate no adverse impact of the nanohybrids on the wheat crop growth [79]. Similarly, the straw yield was enhanced up to $24 \%$ in all the full dose nanohybrids, HAU-75, and ZnHAU-75 in comparison with control treatments, and it was maintained in the rest of the treatments (Fig. 5.9D).

The agronomic traits of the nano-fertilizer treated crop were selectively improved in the few treatments and maintained in all the nanohybrid treatments (Fig. 5.10). The spike length and count were maintained in almost all the nanohybrid treatments as the control treatment (Fig. 5.10A-B). Interestingly, the grain yield was significantly improved up to $22 \%$ in the full dose of nano-fertilizers and was maintained as a control in all other nanohybrids treatments (Fig. 5.10C). The thousand kernel weight was significantly enhanced exclusively in MgHAU-100 and ZnHAU-100 treatments compared with control (Fig. 5.10D). The higher nitrogen doses as nanohybrids ensure better nitrogen availability in the soil and escalate the crop yield. The timings of nitrogen fertilization at different growth stages of the wheat crop are crucial for obtaining optimum yield [80, 81].

The data evince that the $50 \%$ and $75 \%$ nitrogen doses as nanohybrids were adequate as $100 \%$ nitrogen dose as traditional urea fertilizer. The improved crop yield parameters indicate consistent and substantial availability of nitrogen from nanohybrids [82]. The study demonstrates the exceptional benefits of slowrelease nitrogen fertilizer for quality and yield improvement in wheat crops.

\subsubsection{Nanohybrids promote nutrient uptake in wheat}

The nitrogen levels were upsurged in 40 days old wheat leaves treated with full-dose nitrogen as the nanohybrids (Fig. 5.11). The nitrogen uptake enhanced between $13.1-42.62 \%$ in all three $100 \%$ nitrogen as nanohybrids treated plants. All other nanohybrid doses maintained the leaf nitrogen levels as control treatments. The highest leaf nitrogen uptake was observed in the ZnHAU-100 treatments compared with $100 \%$ nitrogen as granular urea fertilizer. Plants require a maximum of $15-30 \%$ of total applied nitrogen throughout their life cycle $[83,84]$. Nitrogen loss from soil through leaching and volatilization is a major reason for the application of a huge amount of chemical fertilizers to the agricultural land for achieving optimum crop yield [84]. Nitrogen loss from agricultural land is also associated with severe environmental and health consequences [85] while the greenhouse gas emission from agricultural activities contributes to one-third of the total emissions [86]. The results demonstrate that even a $50 \%$ nitrogen dose as nanohybrids maintained and significantly enhanced the nitrogen uptake in the wheat crop. Nitrogen nutrient plays a crucial role in plant developmental processes and therefore, nitrogen deficiency at early plant growth can lead to reduced crop yield and growth $[87,88]$. This experimental study shows that sustainable release and constant availability of nitrogen in the soil through nanohybrids promote plant growth and health. The synthesized nanohybrids maintain the crop yield and sufficient nutrient supply while reducing the chemical fertilizer application up to $50 \%$ in wheat crops.

The synthesized nanohybrids consist of nutritional elements such as nitrogen, calcium, phosphorus, zinc, and magnesium. The study demonstrated the nitrogen release from the nanohybrids but there is the possibility that other nutrition elements may release from nanohybrids and become available to plants $[89,90]$. Therefore, macro and micro-elements accumulated in the grain and stem parts of the wheat crop 
after harvesting were analyzed (Fig. 5.12-5.15). All three variants of the nanohybrids are capable of boosting nitrogen supply to the wheat crop at early crop growth stages.

It is interesting to note that nitrogen levels were raised in the wheat grains treated with full nitrogen doses of all three nanohybrids treatments. The grain nitrogen levels were boosted by $51.58 \%, 61.40 \%$, and $78.60 \%$ in the HAU-100, MgHAU-100, and ZnHAU-100, respectively compared with full nitrogen doses of conventional urea fertilizer (Fig. 5.12A). The elevated wheat grain nitrogen is an indicator of crop yield and much required for improving nutritional value in cereals [91, 92]. The grain nitrogen content was maintained as control treatments in the $50 \%$ and $75 \%$ nitrogen treatments as nanohybrids. It is important to understand that lower doses of nitrogen as nanohybrids are not reducing the nitrogen supply to the plants. Enhancement in grain nitrogen accumulation with nitrogen as nanohybrids will directly contribute to economic improvement, and reduced pollution associated with nitrogen fertilization in agriculture [91].

Further, it was noticed that the stem part of wheat accumulated significantly higher levels of nitrogen in all the $100 \%$ nitrogen as nanohybrids treatments (up to $170 \%$ ) compared to control treatments (Fig. 5.12B). The nitrogen content was not significantly altered in $75 \%$ and $50 \%$ nanohybrid treated wheat stem tissues. The results substantiate better nitrogen uptake in wheat through the slow release of the nitrogen from the nanohybrids. Most importantly, $50 \%$ and $75 \%$ doses of nitrogen as nanohybrids delivered sufficient nitrogen to the wheat crop that was comparable with $100 \%$ nitrogen as conventional urea fertilizer. The interaction between nanoparticles and urea molecules allowed slower nitrogen release, reducing the nitrogen loss through volatilization, upraised levels of the nitrogen in the wheat grains, and stem tissues through protracted availability of nitrogen for the plant uptake.

Phosphorus nutrient is a vital component of synthetic fertilizer applications and its deficiency in plants is related to reduced tillering, root development, stunted growth, and disease pressure [93, 94].

Hydroxyapatite nanoparticles can act as a source of phosphorus nutrients and may release phosphorus from the hydroxyapatite nanostructure over time in a slightly acidic environment [35, 95]. The study shows that the grains phosphorus levels were found elevated in all $100 \%$ and $75 \%$ doses of nitrogen as nanohybrids treatments except HAU-75 (Fig. 5.12C). A significantly higher accumulation of phosphorus in the grain tissues was observed by up to $67 \%$ in MgHAU-75, and ZnHAU-75 treated wheat crops. The distorted crystallinity of doped hydroxyapatite could degrade early than hydroxyapatite nanoparticles to release phosphorus $[62,96]$. The half-nitrogen doses as nanohybrids and HAU-75 could maintain the phosphorus levels in the grain tissues. The phosphorus levels in stem tissues were significantly upraised in all the nanohybrid treatments compared with control treatments (Fig. 5.12D). It was previously reported that hydroxyapatite can be used as a source of phosphorus fertilizer $[34,89]$. The degradation of doped and undoped hydroxyapatite through microbial activities could release the phosphorus that is readily available for uptake by the plant [97-99].

The potassium element was significantly increased in wheat grain tissues of $100 \%$ nitrogen doses as nanohybrids treatments and was maintained in remaining doses of the nanohybrids treated grain tissues (Fig. 5.12E). The potassium levels were found significantly elevated in the stem tissues treated with $100 \%$ 
nanohybrids treatments (Fig. 5.12F). It suggests that hydroxyapatite assists the potassium uptake possibly through ion exchange and absorption [100]. Calcium nutrition deficiency in acidic soil leads to damage structural integrity of the plant cell wall, membrane, vacuole, and vital plant physiological processes $[101,102]$. The calcium uptake was improved in the $100 \%$ and $75 \%$ nitrogen nanohybrids treated wheat grains and stems while maintaining in the $50 \%$ nanohybrids treatments (Fig. 5.13A-B). Calcium levels were escalated up to $118 \%$ in the grains and up to $178 \%$ in the stem tissues with the highest surge in ZnHAU treated wheat crop. The enhanced calcium uptake in the wheat plants could be a result of gradual degradation of the hydroxyapatite nanostructure and releasing calcium and phosphorus nutrient which are readily taken up by plants [95]. Likewise, phosphorus, zinc, magnesium from doped and undoped nanohybrids could be released into the soil for the wheat crop.

Magnesium deficiency is usually seen in acidic soil-grown wheat crops where very low levels of exchangeable magnesium negatively affect the wheat crop growth and yield [103]. The magnesium directly affects the vital plant developmental pathways such as photosynthesis and carbohydrate partitioning in crops [104]. The magnesium accumulation was significantly raised exclusively in MgHAU100 treatments of wheat grains while it remained unchanged in most of the nanohybrids treatments (Fig. 5.13C). The results evince that magnesium nanohybrids can deliver magnesium nutrients to the wheat crop in addition to the nitrogen nutrient. It is possible that MgHAU-75 and MgHAU-50 doses due to the lesser quantity, could not change the magnesium levels. The magnesium levels in the stem tissues were maintained in all the nanohybrids treatments as the control treatment (Fig. 5.13D).

Similarly, zinc accumulation was enhanced in all 100\% nitrogen as nanohybrids treatments, MgHAU-75, and $\mathrm{ZnHAU}-75$ while the rest all the treatments could maintain the zinc levels in wheat grains (Fig. 5.14A). The zinc levels were enhanced exclusively in the stem tissues of $75 \%$ nitrogen as nanohybrids treatments (Fig. 5.14B). Zinc plays an important role in the physiological development of cereal crops, especially wheat crops. Moreover, consumption of zinc-deficient food leads to several health issues in the human body [105]. Biofortification of the wheat crop through soil fertilization is the most cost-effective and feasible method [106]. Additional application of zinc nutrients to the soil can be correlated with increased shoot biomass and grain yield in wheat crops [107]. But successful biofortification of the zinc depends on numerous factors such as zinc uptake by plants, root to shoot translocation, and zinc remobilization [106]. Interestingly, only $75 \%$ nitrogen as nanohybrids treatments significantly enhanced while $50 \%$ and $100 \%$ nitrogen as nanohybrids treatments maintained the zinc levels in wheat stem tissues. In the study, zinc-doped hydroxyapatite nanohybrids, not only slowly release nitrogen, but also promote zinc accumulation in wheat plant tissues. Zinc and magnesium-doped hydroxyapatite nanoparticles treated wheat crops were found with enhanced zinc and magnesium levels. The results suggest that zinc and magnesium may release from the hydroxyapatite matrix after degradation in the soil $[90,108]$. The synthesized nanohybrids are multi-nutrient complex that offers a sustainable supply of nitrogen, phosphorus, calcium, magnesium, and zinc.

Interestingly, the nanohybrids treated wheat crop showed improved micronutrient augmentation. The iron levels were hiked up to $40 \%$ in the $100 \%$ and $75 \%$ nitrogen as nanohybrids treatments except for HAU-75 
in wheat grains (Fig. 5.14C). The iron levels were increased up to $110 \%$ in full nitrogen nanohybrids doses treated wheat stem tissues while the $50 \%$ nanohybrids treatments could maintain the iron levels as control treatments (Fig. 5.14D). Particularly, ZnHAU treatments were identified with better iron uptake compared with other nanohybrids and control treatments. The manganese levels of the wheat grain and stem tissues did not change significantly in the nanohybrid treatments (Fig. 5.15A-B). But. copper concentration was increased significantly up to $111 \%$ in the full nitrogen doses as nanohybrids treatments and HAU-75 while maintained in all other nanohybrid treatments in wheat grains (Fig. 5.15C). Wheat stem tissues were observed with higher copper accumulation up to $51 \%$ in $100 \%$ and $75 \%$ nitrogen as nanohybrids treatments (Fig. 5.15D).

Iron and copper were not supplied as nanohybrids but were noticed with enhanced uptake of these elements. Hydroxyapatite nanoparticles exhibit high surface area and porous structure that can adsorb iron and copper ions from the soil $[109,110]$. These adsorbed ions can be released after degradation of the hydroxyapatite and are available for the wheat crop. The adsorbed iron and copper may also settle in the lattice structure of the hydroxyapatite that may be readily available for the crops to uptake [109]. The hydroxyapatite-urea, magnesium-doped hydroxyapatite-urea, and zinc-doped hydroxyapatite-urea nanohybrids demonstrate the slow release of nitrogen in the soil environment, stay in the soil for a longer time, and efficiently deliver nitrogen to the wheat crop.

Additionally, the nanostructures are such a complex multi-nutrient complex that is efficient for the delivery of several macro-and micro-nutrients to the wheat crop. Surprisingly, lower nitrogen doses as nanohybrids were effectively maintaining the nitrogen uptake, other nutrient molecules present in the backbone structure was delivered, and a few micro-nutrients such as iron, copper which were not present in the doped or undoped nanohybrids were found to be enhanced in wheat crop demonstrating multi-purpose use of nanohybrids. The nanohybrids can enable farmers to apply just one dose of the synthesized nanohybrids which may deliver nitrogen, phosphorus, calcium, magnesium, and zinc nutrients.

This comprehensive study demonstrates a cost-effective and rapid synthesis of nanoscale undoped hydroxyapatite and $\mathrm{Mg}$ and $\mathrm{Zn}$ doped hydroxyapatite as an efficient carrier of nitrogen nutrients for the wheat crop. The nitrogen from the nanohybrids slowly releases and remains for a longer time in the soil compared to granular urea fertilizer. Most importantly, all three hydroxyapatite variants used in this study substantially curtail the amount of chemical fertilizers applied to the agricultural land and avoid nitrogen losses that aid in mitigating environmental pollution without compromising crop growth, quality, and yield. In addition, the nanohybrids act as a source of calcium, phosphorus, magnesium, zinc, and iron nutrient elements for achieving optimum growth and development of the wheat crop.

\section{Discussion}

Crop production is associated with the utilization of natural resources such as soil, water, climate, land space, and energy [111]. In modern agriculture practices, crop fertilization is a vital agrotechnical parameter for achieving optimum crop yield and quality $[83,84,111]$. In developing countries, the 
excessive and indiscriminative application of chemical fertilizer has been a very common agriculture practice to intensify crop yield $[8,112]$. The surplus nitrogen in the agricultural fields fosters residual nitrate accumulation and leaching into groundwaters, adversely affects crop and fruit quality, and encourages greenhouse gas emissions $[8,13,15,18]$. Therefore, controlling the chemical fertilizers inputs, especially nitrogen fertilizer, is imperative to forestall environmental and agricultural degradation [8].

Improving nitrogen use efficiency through nutrient management can mitigate, the environmental release of toxic nitrogen compounds, soil health, and crop quality and yield [8,91]. Slow-release fertilizers are one of the most attractive tools for turning down the chemical load into agricultural fields [72].

Nanomaterials-based slow-released fertilizers are the most recent and advanced version of slow-release fertilizers, which utilize the extraordinary properties of nano-scale materials to ameliorate the fertilizer performance and restrain the rapid loss in soil and water [71, 72].

This work demonstrates the potential of the hydroxyapatite nanoparticles as a nitrogen nutrient delivery vehicle as well as a biodegradable multi-nutrient complex for plants. Additionally, the hydroxyapatite nanoparticles were doped with magnesium and zinc to expand the nitrogen transport capability, alter nitrogen release behavior, and integrate zinc, and magnesium nutrient elements for biofortification. A total of three nanoparticles, hydroxyapatite, magnesium doped, and zinc doped hydroxyapatite, were synthesized, and investigated for nitrogen loading, and release behavior properties. Finally, the different dosages of the urea-nanohybrids were supplied as nitrogen fertilizer and compared with conventional chemical nitrogen fertilizer for optimum nitrogen delivery to the wheat crop.

The XRD data showed structural deformities and size reduction in the zinc and magnesium doped hydroxyapatite nanoparticles. The zinc and magnesium ions replace the calcium ions in the hydroxyapatite crystal lattice to provoke defacement of the hydroxyapatite crystal surface evidenced by lowered peak intensities and peak widening. The zinc and magnesium ions are smaller than calcium ions and they adjust the molecular interactions and transform the nanocrystal surface. The previous reports on doped nanoparticles show that smaller ions introduce significant alterations in the nanomaterial properties $[113,114]$.

Further, FTIR analysis confirms the presence of the urea and hydroxyapatite characteristic functional groups. The microscopic analysis revealed the transformation of the morphology of the nanoparticles from rod-shaped to round or irregular round-shaped structures. The doped nanohybrids were smaller than the undoped nanohybrids. The particles size analysis results in a relatively larger average hydrodynamic diameter than measured from microscopic studies because nanoparticles attract each other by strong hydrophilic interactions on the surface and are identified as clusters [115]. The zeta potential of the nanohybrids suggests instability and agglomeration in the water solvent.

The urea release kinetics demonstrated the slow release of urea from nanohybrids in the soil matrix under constant water flow. Nanohybrids release urea molecules up to 320 hours compared with 30 minutes of burst release of granular urea. The urea-nanoparticles interaction altered the urea-free energy change of dissolution in the water [59] and the nanoparticles interfere with the cavity formation capabilities of the 
urea in the water environment that reduce its dissolution in water $[63,64]$. The surrounding water molecules require more energy to create a cavity to dissolve urea due to the presence of nanomaterials [65]. These results present extended urea release capabilities of the nanohybrids compared with urea granules. The urea release from the nanohybrids follows the Hixson-Crowell model equation. The urea molecules dissolution took place on planes parallel to the surface, which decreases proportionally over time [70]. The urea release was limited by the dissolution velocity and the dimension of the nanohybrids was gradually decreased with urea molecules disassociation in the water.

The nanohybrids treated wheat crops showed improved growth parameters and nutrient augmentation in $100 \%$ nitrogen as nanohybrids treatments while at least maintained in the $50 \%$ and $75 \%$ nitrogen as nanohybrids treatments. The wheat grain tissues were observed with significantly elevated magnesium levels in MgHAU-100 treatments suggesting release and plant uptake of the doped magnesium from hydroxyapatite. The zinc element uptake was enhanced in not just only zinc-doped hydroxyapatite, but also magnesium-doped hydroxyapatite treated wheat crop grains that indicate zinc release from hydroxyapatite like magnesium-doped hydroxyapatite and zinc adsorption. Similarly, iron and copper uptake were increased in the nanohybrids treated wheat grain and stem tissues. The hydroxyapatite, due to its high surface area and porous structure, may adsorb the metal ions such as iron, copper, and zinc from the soil and make it available for plant uptake $[109,110]$. These adsorbed ions can be released after degradation of the hydroxyapatite and were available for the wheat crop [116]. Additionally, the adsorbed metal ions may also settle in the lattice structure of the hydroxyapatite that may be available for the crops to uptake [109].

This study demonstrated the synthesis and application of the slow-nitrogen releasing urea-nanohybrids for delivering nitrogen nutrients to the wheat crop. The nanohybrids reduce the nitrogen fertilizer application to half for obtaining equivalent crop growth and nitrogen bioavailability to $100 \%$ dose of nitrogen as conventional urea fertilizer.

\section{Conclusion}

Uncontrolled application of nitrogen fertilizers to agricultural land not only causes environmental pollution but also degrades soil for future agricultural use. Soil degradation, nitrate, and heavy metals accumulation in the soil interfere with soil fertility and affect crop yield and quality. Targeted delivery of nitrogen to the crops through means of slow-release nitrogen fertilizers could offer an alternative to conventional nitrogen fertilization. The hydroxyapatite mineral is an environmentally safe, and biocompatible compound. The doping of hydroxyapatite brings in few variations in the structure that alter the urea interaction with nanoparticles and integrate magnesium and zinc nutrients. The slow nitrogenreleasing nanohybrids supply sufficient nitrogen to the wheat crop on time which turns out to be a better source of nitrogen. The slow urea release from the nanohybrids ensure timely supply of the nitrogen to the wheat crop and long-term availability. The $50 \%$ and $75 \%$ nitrogen dose as nanohybrids maintained the wheat crop growth and nutrient compositions. The nitrogen as nanohybrids stays for a longer time in the soil and release nitrogen for crop uptake throughout the wheat crop life cycle. The nanohybrids 
substantially reduce the nitrogen inputs to half while elevating additional nutritional elements such as phosphorus, calcium, zinc, magnesium, and iron in crops. The nanohybrids as multi-nutrient complexes serve as a source of nutrients as well as carrier molecules for nitrogen nutrients. This study provides a detailed analysis of synthesis, characterization of the nitrogenous nanohybrids for nitrogen nutrients delivery to the wheat crop. This work exemplifies the potential of the hydroxyapatite nanoparticles as an environmentally friendly nutrient carrier for agricultural and environmental applications. To date, no study recognizes chemical doping-based nanomaterial manipulation for agricultural applications. This thesis, through a comprehensive study, have exemplified the advantages of 'doping' as a method for tailoring nanoparticle properties for extended agricultural and environmental applications.

\section{Material And Methods}

\section{Nanomaterial synthesis}

The hydroxyapatite nanoparticles were synthesized according to the previous report with few modifications [117]. Briefly, one molar calcium hydroxide aqueous solution was mixed at $400 \mathrm{rpm}$ for half an hour while maintaining the solution temperature of $50^{\circ} \mathrm{C}$. Further, 0.6 molars phosphoric acid was added dropwise to the suspension, stirred for two hours, and the resulting suspension was dried at $65^{\circ} \mathrm{C}$ for 10 hours. To synthesize magnesium and zinc doped hydroxyapatite nanoparticles, 0.05 molar magnesium chloride, and 0.05 molar zinc sulphate was mixed with 0.95 molar calcium hydroxide, separately and 0.6 molars phosphoric acid was slowly added to the suspensions. The resulting suspensions were stirred for two hours at $50^{\circ} \mathrm{C}$ and dried at $65^{\circ} \mathrm{C}$ for 10 hours.

For the synthesis of the urea-hydroxyapatite nanohybrids, seven molar urea was slowly dissolved in water and mixed with one molar calcium hydroxide with continuous stirring at $400 \mathrm{rpm}$ for an hour and reaction temperature was adjusted to $50^{\circ} \mathrm{C}$. For the synthesis of the magnesium doped hydroxyapatite-urea and zinc doped hydroxyapatite-urea nanohybrids, 0.95 molar calcium hydroxide, 0.05 molar magnesium chloride, and 0.05 molar zinc sulphate were mixed separately at $400 \mathrm{rpm}$ for an hour and reaction temperature was adjusted to $50^{\circ} \mathrm{C}$. 0.6 molar phosphoric acid was slowly added to the suspension. The resulting suspension was stirred for three hours at $50^{\circ} \mathrm{C}$ and dried at $65^{\circ} \mathrm{C}$ for 24 hours.

\section{Nanomaterial characterization \\ Powder X-ray diffraction (PXRD)}

Powder X-ray diffraction (PXRD) of the dried samples was carried out on a Bruker D8 Advance diffractometer. The monochromatic Ni-filtered Cu Ka radiation $(\lambda=1.54 \AA)$ was used for the analysis.

\section{Fourier Transform Infrared (FTIR)}

FTIR analysis was performed on a Varian 7000 FTIR machine and the FTIR spectrum was obtained in the region 4000 to $400 \mathrm{~cm}^{-1}$ using the $\mathrm{KBr}$-disc method for sample preparation. 


\section{Cryo-transmission electron microscopy (Cryo-TEM) and Energy-dispersive X-ray analysis (EDX)}

TEM images of the samples were obtained on a TALOS cryo transmission electron microscope at an accelerating voltage of $200 \mathrm{kV}$. The samples were dispersed in MiliQ water, sonicated for 15 minutes, drop cast on carbon-coated copper grids (300 mesh), and incubated for one hour at room temperature. Energydispersive X-ray analysis (EDX) of the samples was performed on the TALOS machine using a highenergy beam accelerating voltage of $15 \mathrm{kV}$.

\section{Scanning electron microscopy (SEM)}

The SEM images of the dried samples were acquired on the TESCAN LYRA3 machine, a focused ion beam scanning electron microscope. The dried sample powder was sprinkled on a black carbon tape surface on steel grids and the samples were coated with ultrathin electrically conducting gold metal before imaging.

\section{UV-Visible spectrophotometric analysis (UV-Vis)}

UV-vis spectrum of the synthesized bare particles and nanohybrids were obtained on a Labman UVvisible spectrophotometer.

\section{Hydrodynamic particle size (DLS) and zeta potential}

The average hydrodynamic diameter and zeta potential of the synthesized urea-nanohybrids and bare nanoparticles using Horiba Particle Analyzer SZ-100V2 instrument.

\section{Soil experimental characteristics}

The experimental soil for the field and urea release study is classified as Ustochrept in the order of Inceptisol. The texture of surface experimental soil $(0-15 \mathrm{~cm})$ was a sandy clay-loam soil $(50.8 \%$ sand, $23.2 \%$ silt, and $25.9 \%$ clay) determined by the hydrometer method [118]. The experimental soil consists of $225 \mathrm{~kg} \mathrm{ha}^{-1}$ alkaline permanganate oxidizable nitrogen (N) [119], $12.2 \mathrm{~kg} \mathrm{ha}^{-1}$ available phosphorus (P) [120], $226 \mathrm{~kg} \mathrm{ha}^{-1} 1 \mathrm{~N}$ ammonium acetate exchangeable potassium (K) [121] and $5.5 \mathrm{~g} \mathrm{~kg}^{-1}$ organic carbon (C) [122]. The pH of the soil was 7.9 (1:2.5 soil: water ratio) [123] and diethylene triamine penta acetic acid (DTPA)-extractable zinc [124] in soil was $0.63 \mathrm{mg} \mathrm{kg}^{-1}$ soil. Fifty kilograms of virgin surface soil from the experimental field were collected and passed through a $2 \mathrm{~mm}$ sieve and used for the urea release kinetics experiment.

\section{Urea release kinetics}

Urea molecule release from nanohybrids in soil environment was evaluated in a closed column with a diameter of $30 \mathrm{~mm} \times 100 \mathrm{~mm}$ filled with homogenous soil particles (up to $40 \mathrm{~mm}$ ). One gram of hydroxyapatite-urea (HAU), magnesium-doped hydroxyapatite-urea (MgHAU), zinc-doped hydroxyapatiteurea ( $\mathrm{ZnHAU})$, and urea granules were placed in the middle of the soil bed of four different soil-filled columns. Additionally, a filter was placed at the bottom of the column to avoid the unnecessary escape of 
soil in the elution. The column was connected to a hydraulic pump for the continuous supply of distilled water into the column at the rate of $2 \mathrm{ml}$ per minute and the elute was collected at different time intervals (up to 320 hours) for estimation of released urea. The collected elute was immediately processed for urea estimation through the DAM method $[125,126]$. The urea release from urea granules and nanohybrids was compared and studied through Hixson-Crowell model equation [70].

\section{Wheat crop field experiment}

The field experiment was conducted during the Rabi season (wheat) of 2019-20 at the research farm of Indian Agricultural Research Institute, New Delhi, which is located at $28.08^{\circ} \mathrm{N}$ latitude and $77.12^{\circ} \mathrm{E}$ longitudes in central Delhi with an elevation of $228.61 \mathrm{~m}$ above mean sea level. The experiment was laid out in randomized block design (RBD) containing twelve treatments namely, i) No fertilizers, ii) Granular urea $100 \% \mathrm{RD}_{\mathrm{NPK}}\left(100 \%\right.$ of recommended $\mathrm{N}$ dose), iii) Hydroxyapatite-urea $50 \% \mathrm{RD}_{\mathrm{N}}+100 \% \mathrm{RD}_{\mathrm{PK}}(50 \%$ of recommended $\mathrm{N}$ dose), iv) Mg-doped Hydroxyapatite-urea $50 \% \mathrm{RD}_{\mathrm{N}}+100 \% \mathrm{RD}_{\mathrm{PK}}(50 \%$ of recommended $N$ dose), v) Zn doped Hydroxyapatite-urea $50 \% \mathrm{RD}_{\mathrm{N}}+100 \% \mathrm{RD}_{\mathrm{PK}}(50 \%$ of recommended $\mathrm{N}$ dose), vi) Hydroxyapatite-urea $75 \% \mathrm{RD}_{\mathrm{N}}+100 \% \mathrm{RD}_{\mathrm{PK}}(75 \%$ of recommended $\mathrm{N}$ dose), vii) Mg-doped Hydroxyapatite-urea $75 \% \mathrm{RD}_{\mathrm{N}}+100 \% \mathrm{RD}_{\mathrm{PK}}$ (75\% of recommended $\mathrm{N}$ dose), viii) $\mathrm{Zn}$ doped Hydroxyapatite-urea $75 \% \mathrm{RD}_{\mathrm{N}}+100 \% \mathrm{RD}_{\mathrm{PK}}$ (75\% of recommended $\mathrm{N}$ dose), ix) Hydroxyapatite-urea $100 \% \mathrm{RD}_{\mathrm{N}}+100 \% \mathrm{RD}_{\mathrm{PK}}\left(100 \%\right.$ of recommended $\mathrm{N}$ dose), $\mathrm{x}$ ) Mg-doped Hydroxyapatite-urea $100 \% \mathrm{RD}_{\mathrm{N}}+$ $100 \% \mathrm{RD}_{\mathrm{PK}}\left(100 \%\right.$ of recommended $\mathrm{N}$ dose) and, xi) Zn doped Hydroxyapatite-urea $100 \% \mathrm{RD}_{\mathrm{N}}+100 \%$ $\mathrm{RD}_{\mathrm{PK}}(100 \%$ of recommended $\mathrm{N}$ dose), xii) No Nitrogen. For wheat, the recommended $\mathrm{N}$ dose of $150 \mathrm{~kg} \mathrm{~N}$ per hectare was supplied. The phosphorus and potassium were applied as single super phosphate (SSP$\left.16 \% \mathrm{P}_{2} \mathrm{O}_{5}\right)\left(60 \mathrm{~kg} \mathrm{P}_{2} \mathrm{O}_{5}\right.$ per hectare) and Muriate of potash (MOP-60 \% $\left.\mathrm{K}_{2} \mathrm{O}\right)(60 \mathrm{~kg}$ per hectare), respectively as per recommendation in all the treatments uniformly. All the treatments were replicated three times. The full dose of the phosphorus and potassium fertilizers was applied as a basal dose at the time of sowing. All the nitrogen fertilizers were applied in two installments, half of the dose at the time of sowing and the remaining half dose at the time of tillering.

Wheat seeds variety HD 3086 was used in the study. All the treatments were implemented in a $6(3 \mathrm{~m} \mathrm{X}$ $2 \mathrm{~m}$ ) square meters size research plot. The wheat crop was grown in the Rabi (winter) season (22nd November 2019 to 30th April 2020). The soil sampling was performed at the time of harvesting for the ammoniacal and nitrate nitrogen release and available nitrogen study. The crop was maintained with regular irrigation and other agronomical practices. The plant height, number of effective tillers, spike length, spike count, NDVI level, straw yield, grain yield, and 1000-grain weight were recorded after harvesting the crop. The grain and straw samples of wheat were dried at $70^{\circ} \mathrm{C}$ and processed for the elemental (phosphorus, nitrogen, potassium, calcium, magnesium, zinc, iron, manganese, and copper) after harvesting.

\section{Elemental analysis}


Total nitrogen estimation in the plant tissues was performed using the Kjeldahl method [127]. The total available nitrogen in the soil was estimated through the Kjeldahl method using alkaline potassium permanganate as an oxidative agent $[119,128]$. Total plant phosphorus was estimated using the phosphovanado-molybdate method [129]. Total calcium [130] and potassium [131] were estimated using a flame photometer. Magnesium was estimated using the EDTA titration method [132]. The zinc, manganese, copper, and iron were estimated using atomic absorption spectrophotometer $[133,134]$. Total grain protein [135], phospholipid [136], and proline [137] content were estimated for the assessment of grain quality.

\section{Statistical analysis}

The values are provided as mean \pm standard deviation and statistical significance was calculated by one-

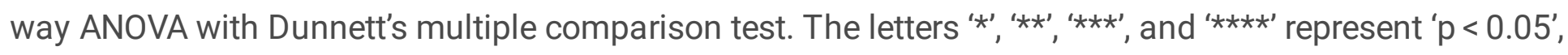
' $p<0.01$ ', ' $p<0.001$ ', and ' $p<0.0001$ ', respectively and 'ns' represents 'not significant'.

\section{Declarations}

\section{Ethics approval and consent to participate}

Not Applicable.

\section{Consent for publication}

Not Applicable.

\section{Availability of data and materials}

All data generated or analysed during this study are included in this published article.

\section{Competing interests}

The authors declare that they have no known competing financial interests.

\section{Funding}

BS was supported by Deakin University Postgraduate Scholarship.

\section{Authors' contributions}


Bhaskar Sharma: conceptualization, design of methodology, investigation/experimentations, protocols, data collection curation, formal analysis, validation, visualization, writing- original draft, writing- review, and editing (revision) of the manuscript Manoj Shrivastava: field study, critical revision of the manuscript Luis Afonso: critical revision of the manuscript Udit Soni: supervision, conceptualization, methodology, protocols, critical revision of the manuscript, project funding David Cahill: supervision, project funding, critical revision of the manuscript.

\section{Acknowledgments}

This work was jointly supported by Deakin University, Australia, and TERI School of Advanced Studies, India. We are thankful to Indian Agriculture Research Institute, New Delhi for providing necessary resources and assistance in the field experiments. We are grateful to Dr. Chaithanya Madhurantakam, Associate Professor, TERI SAS for providing basic research facilities. Authors thank JNU AIRF, and AlIMS SAIF for XRD, FTIR, SEM, TEM, and EDX facilities.

\section{References}

1. Lee R. The outlook for population growth. Science. 2011;333(6042):569-73.

2. Desa U: United nations department of economic and social affairs, population division. world population prospects: The 2015 revision, key findings and advance tables. Online Edition UN DESA, New York 2015.

3. Alexandratos N, Bruinsma J: World agriculture towards 2030/2050: The 2012 Revision. 2012.

4. van Dijk M, Morley T, Rau ML, Saghai Y. A meta-analysis of projected global food demand and population at risk of hunger for the period 2010-2050. Nature Food. 2021;2(7):494-501.

5. Tian X, Engel BA, Qian H, Hua E, Sun S, Wang Y. Will reaching the maximum achievable yield potential meet future global food demand? J Clean Prod. 2021;294:126285.

6. Liu Y, Pan X, Li J. Current Agricultural Practices Threaten Future Global Food Production. J Agric Environ Ethics. 2015;28(2):203-16.

7. Matson PA, Parton WJ, Power AG, Swift MJ. Agricultural intensification and ecosystem properties. Science. 1997;277(5325):504-9.

8. Dimkpa CO, Fugice J, Singh U, Lewis TD. Development of fertilizers for enhanced nitrogen use efficiency-Trends and perspectives. Sci Total Environ. 2020;731:139113.

9. Good AG, Beatty PH. Fertilizing nature: a tragedy of excess in the commons. PLoS Biol. 2011;9(8):e1001124.

10. Hussain S, Mielke L, Skopp J. Detachment of soil as affected by fertility management and crop rotations. Soil Sci Soc Am J. 1988;52(5):1463-8.

11. Savci S. Investigation of Effect of Chemical Fertilizers on Environment. APCBEE Procedia. 2012;1:287-92. 
12. Witte C-P. Urea metabolism in plants. Plant Sci. 2011;180(3):431-8.

13. Shelton RE, Jacobsen KL, McCulley RL. Cover crops and fertilization alter nitrogen loss in organic and conventional conservation agriculture systems. Front Plant Sci. 2018;8:2260.

14. Hakeem KR, Sabir M, Ozturk M, Akhtar MS, Ibrahim FH. Nitrate and Nitrogen Oxides: Sources, Health Effects and Their Remediation. Rev Environ Contam Toxicol. 2017;242:183-217.

15. Xu R, Tian H, Pan S, Prior SA, Feng Y, Batchelor WD, Chen J, Yang J. Global ammonia emissions from synthetic nitrogen fertilizer applications in agricultural systems: Empirical and process-based estimates and uncertainty. Glob Change Biol. 2019;25(1):314-26.

16. Pavlou GC, Ehaliotis CD, Kavvadias VA. Effect of organic and inorganic fertilizers applied during successive crop seasons on growth and nitrate accumulation in lettuce. Sci Hortic. 2007;111(4):319-25.

17. Stevens CJ. Nitrogen in the environment. Science. 2019;363(6427):578-80.

18. Wang X, Fan J, Xing Y, Xu G, Wang H, Deng J, Wang Y, Zhang F, Li P, Li Z. The effects of mulch and nitrogen fertilizer on the soil environment of crop plants. Adv Agron. 2019;153:121-73.

19. Trenkel ME. Controlled-release and stabilized fertilizers in agriculture. Vol. 11: International Fertilizer Industry Association Paris; 1997.

20. Kirchmann H, Bergström L. DO ORGANIC FARMING PRACTICES REDUCE NITRATE LEACHING? Commun Soil Sci Plant Anal. 2001;32(7-8):997-1028.

21. Khan I, Saeed K, Khan I. Nanoparticles: Properties, applications and toxicities. Arabian Journal of Chemistry. 2019;12(7):908-31.

22. Sanvicens N, Marco MP. Multifunctional nanoparticles-properties and prospects for their use in human medicine. Trends Biotechnol. 2008;26(8):425-33.

23. Christian P, Von der Kammer F, Baalousha M, Hofmann T. Nanoparticles: structure, properties, preparation and behaviour in environmental media. Ecotoxicology. 2008;17(5):326-43.

24. González-Melendi P, Fernández-Pacheco R, Coronado MJ, Corredor E, Testillano P, Risueño MC, Marquina C, Ibarra MR, Rubiales D, Pérez-de-Luque A. Nanoparticles as smart treatment-delivery systems in plants: assessment of different techniques of microscopy for their visualization in plant tissues. Ann Bot. 2008;101(1):187-95.

25. Wang X, Ma G, Tian X, Wang Y. Effects of NMUrea on rice yield and agronomic nitrogen efficiency. Plant Nutrition Fertilizer Science. 2010;16(6):1479-85.

26. Songkhum P, Wuttikhun T, Chanlek N, Khemthong P, Laohhasurayotin K. Controlled release studies of boron and zinc from layered double hydroxides as the micronutrient hosts for agricultural application. Appl Clay Sci. 2018;152:311-22.

27. Priyanka N, Geetha N, Ghorbanpour M, Venkatachalam P: Role of engineered zinc and copper oxide nanoparticles in promoting plant growth and yield: present status and future prospects. In: Advances in Phytonanotechnology. Elsevier; 2019: 183-201. 
28. Elanchezhian R, Kumar D, Ramesh K, Biswas AK, Guhey A, Patra AK. Morpho-physiological and biochemical response of maize (Zea mays L.) plants fertilized with nano-iron (Fe304) micronutrient. J Plant Nutr. 2017;40(14):1969-77.

29. Kasivelu G, Selvaraj T, Malaichamy K, Kathickeyan D, Shkolnik D, Chaturvedi S: Nano-micronutrients [Y-Fe 203 (iron) and ZnO (zinc)]: green preparation, characterization, agro-morphological characteristics and crop productivity studies in two crops (rice and maize). New Journal of Chemistry 2020, 44(26):11373-11383.

30. Turon P, Del Valle LJ, Alemán C, Puiggalí J. Biodegradable and biocompatible systems based on hydroxyapatite nanoparticles. Applied Sciences. 2017;7(1):60.

31. Szcześ A, Hołysz L, Chibowski E. Synthesis of hydroxyapatite for biomedical applications. Adv Coll Interface Sci. 2017;249:321-30.

32. Ibrahim M, Labaki M, Giraudon J-M, Lamonier J-F. Hydroxyapatite, a multifunctional material for air, water and soil pollution control: A review. J Hazard Mater. 2020;383:121139.

33. Kim DW, Cho I-S, Kim JY, Jang HL, Han GS, Ryu H-S, Shin H, Jung HS, Kim H, Hong KS. Simple largescale synthesis of hydroxyapatite nanoparticles: in situ observation of crystallization process. Langmuir. 2010;26(1):384-8.

34. Montalvo D, McLaughlin MJ, Degryse F. Efficacy of hydroxyapatite nanoparticles as phosphorus fertilizer in andisols and oxisols. Soil Sci Soc Am J. 2015;79(2):551-8.

35. Taşkın MB, Şahin Ö, Taskin H, Atakol O, Inal A, Gunes A. Effect of synthetic nano-hydroxyapatite as an alternative phosphorus source on growth and phosphorus nutrition of lettuce (Lactuca sativa L.) plant. J Plant Nutr. 2018;41(9):1148-54.

36. Kottegoda N, Sandaruwan C, Priyadarshana G, Siriwardhana A, Rathnayake UA, Berugoda Arachchige DM, Kumarasinghe AR, Dahanayake D, Karunaratne V, Amaratunga GA. Ureahydroxyapatite nanohybrids for slow release of nitrogen. ACS Nano. 2017;11(2):1214-21.

37. Kalita SJ, Bhardwaj A, Bhatt HA. Nanocrystalline calcium phosphate ceramics in biomedical engineering. Materials Science Engineering: C. 2007;27(3):441-9.

38. Yuan X, Zhu B, Tong G, Su Y, Zhu X. Wet-chemical synthesis of Mg-doped hydroxyapatite nanoparticles by step reaction and ion exchange processes. Journal of Materials Chemistry B. 2013;1(47):6551-9.

39. Kim H, Mondal S, Bharathiraja S, Manivasagan P, Moorthy MS, Oh J. Optimized Zn-doped hydroxyapatite/doxorubicin bioceramics system for efficient drug delivery and tissue engineering application. Ceram Int. 2018;44(6):6062-71.

40. Zhao S-N, Yang D-L, Wang D, Pu Y, Le Y, Wang J-X, Chen J-F. Design and efficient fabrication of micro-sized clusters of hydroxyapatite nanorods for dental resin composites. Journal of Materials Science. 2019;54(5):3878-92.

41. Nobre CMG, Pütz N, Hannig M: Adhesion of hydroxyapatite nanoparticles to dental materials under oral conditions. Scanning 2020, 2020. 
42. Poinern G, Brundavanam R, Le XT, Djordjevic S, Prokic M, Fawcett D. Thermal and ultrasonic influence in the formation of nanometer scale hydroxyapatite bio-ceramic. Int J Nanomed. 2011;6:2083.

43. Sagle LB, Zhang Y, Litosh VA, Chen X, Cho Y, Cremer PS. Investigating the hydrogen-bonding model of urea denaturation. J Am Chem Soc. 2009;131(26):9304-10.

44. Pimentel GC. Hydrogen Bonding and Electronic Transitions: The Role of the Franck-Condon Principle. J Am Chem Soc. 1957;79(13):3323-6.

45. Hammond JL, Bhalla N, Rafiee SD, Estrela P. Localized surface plasmon resonance as a biosensing platform for developing countries. Biosensors (Basel). 2014;4(2):172-88.

46. Haiss W, Thanh NT, Aveyard J, Fernig DG. Determination of size and concentration of gold nanoparticles from UV-vis spectra. Anal Chem. 2007;79(11):4215-21.

47. Predoi D, Iconaru SL, Predoi MV, Motelica-Heino M, Guegan R, Buton N. Evaluation of Antibacterial Activity of Zinc-Doped Hydroxyapatite Colloids and Dispersion Stability Using Ultrasounds. Nanomaterials. 2019;9(4):515.

48. Robertson GP, Groffman P. Nitrogen transformations. In: Soil microbiology, ecology and biochemistry. Elsevier; 2007. pp. 341-64.

49. Fierer N, Schimel JP. Effects of drying-rewetting frequency on soil carbon and nitrogen transformations. Soil Biol Biochem. 2002;34(6):777-87.

50. Liang X, Chen Y, Li H, Tian G, Ni W, He M, Zhang Z. Modeling transport and fate of nitrogen from urea applied to a near-trench paddy field. Environ Pollut. 2007;150(3):313-20.

51. Sanz-Cobena A, Sánchez-Martín L, García-Torres L, Vallejo A. Gaseous emissions of N2O and NO and N03 - leaching from urea applied with urease and nitrification inhibitors to a maize (Zea mays) crop. Agr Ecosyst Environ. 2012;149:64-73.

52. Hanson BR, Šimůnek J, Hopmans JW. Evaluation of urea-ammonium-nitrate fertigation with drip irrigation using numerical modeling. Agric Water Manag. 2006;86(1-2):102-13.

53. Stumpe MC, Grubmüller H. Aqueous urea solutions: structure, energetics, and urea aggregation. J Phys Chem B. 2007;111(22):6220-8.

54. Masunov A, Dannenberg J. Theoretical study of urea. I. Monomers and dimers. The Journal of Physical Chemistry A. 1999;103(1):178-84.

55. Chitra R, Smith PE. Molecular dynamics simulations of the properties of cosolvent solutions. J Phys Chem B. 2000;104(24):5854-64.

56. Taniewska-Osińska S, Piestrzyńska B, Łogwinienko R. The enthalpy of solution of $\mathrm{Nal}, \mathrm{NaCl}, \mathrm{NaClO4}$, and urea in water-tetrahydrofuran mixtures at 298.15 K. Can J Chem. 1980;58(15):1584-8.

57. Lee C, Stahlberg EA, Fitzgerald G. Chemical structure of urea in water. The Journal of Physical Chemistry. 1995;99(50):17737-41.

58. Graziano G. Probability of cavity creation in water and corresponding Lennard-Jones liquid. J Mol Liq. 2017;229:358-61. 
59. Ramondo F, Bencivenni L, Caminiti R, Pieretti A, Gontrani L. Dimerisation of urea in water solution: a quantum mechanical investigation. Physical Chemistry Chemical Physics. 2007;9(18):2206-15.

60. Wang F, Alva A. Leaching of nitrogen from slow-release urea sources in sandy soils. Soil Sci Soc Am J. 1996;60(5):1454-8.

61. Sigurdarson JJ, Svane S, Karring $\mathrm{H}$. The molecular processes of urea hydrolysis in relation to ammonia emissions from agriculture. Reviews in Environmental Science Bio/Technology. 2018;17(2):241-58.

62. Dasgupta S, Banerjee SS, Bandyopadhyay A, Bose S. Zn-and Mg-doped hydroxyapatite nanoparticles for controlled release of protein. Langmuir. 2010;26(7):4958-64.

63. Godawat R, Jamadagni SN, Garde S: Characterizing hydrophobicity of interfaces by using cavity formation, solute binding, and water correlations. Proceedings of the National Academy of Sciences 2009, 106(36):15119-15124.

64. Postma JP, Berendsen HJ, Haak JR. Thermodynamics of cavity formation in water. A molecular dynamics study. In: Faraday Symposia of the Chemical Society: 1982. Royal Society of Chemistry: 55-67.

65. Madan B, Lee B. Role of hydrogen bonds in hydrophobicity: the free energy of cavity formation in water models with and without the hydrogen bonds. Biophys Chem. 1994;51(2-3):279-89.

66. Ma J, Qin J. Graphene-like Zinc Substituted Hydroxyapatite. Cryst Growth Des. 2015;15(3):1273-9.

67. Sun JP, Song Y. Strengthening Adhesion of the Hydroxyapatite and Titanium Interface by Substituting Silver and Zinc: A First Principles Investigation. ACS Applied Nano Materials. 2018;1(9):4940-54.

68. Wang $X$, Wu H, Cheng $X$, Yang M, Zhang L. Probing the surface activity of hydroxyapatite nanoparticles through their interaction with water molecules. AIP Adv. 2020;10(6):065217.

69. Bose S, Vu AA, Emshadi K, Bandyopadhyay A. Effects of polycaprolactone on alendronate drug release from $\mathrm{Mg}$-doped hydroxyapatite coating on titanium. Materials Science Engineering: C. 2018;88:166-71.

70. Hixson A, Crowell J. Dependence of reaction velocity upon surface and agitation. Industrial Engineering Chemistry. 1931;23(8):923-31.

71. Xiaoyu N, Yuejin W, Zhengyan W, Lin W, Guannan Q, Lixiang Y. A novel slow-release urea fertiliser: Physical and chemical analysis of its structure and study of its release mechanism. Biosys Eng. 2013;115(3):274-82.

72. Naz MY, Sulaiman SA. Slow release coating remedy for nitrogen loss from conventional urea: a review. J Controlled Release. 2016;225:109-20.

73. Azeem B, KuShaari K, Man ZB, Basit A, Thanh TH. Review on materials \& methods to produce controlled release coated urea fertilizer. J Controlled Release. 2014;181:11-21.

74. Soares JR, Cantarella H, de Campos Menegale ML. Ammonia volatilization losses from surfaceapplied urea with urease and nitrification inhibitors. Soil Biol Biochem. 2012;52:82-9. 
75. Ernst J, Massey $\mathrm{H}$. The effects of several factors on volatilization of ammonia formed from urea in the soil. Soil Sci Soc Am J. 1960;24(2):87-90.

76. Masle J: Competition Among Tillers in Winter Wheat: Consequences for Growth and Development of the Crop. In: Wheat Growth and Modelling. Edited by Day W, Atkin RK. Boston, MA: Springer US; 1985: 33-54.

77. Ishag $\mathrm{H}$, Taha M. Production and survival of tillers of wheat and their contribution to yield. The Journal of Agricultural Science. 1974;83(1):117-24.

78. Weisz R, Crozier CR, Heiniger RW. Optimizing Nitrogen Application Timing in No-Till Soft Red Winter Wheat. Agron J. 2001;93(2):435-42.

79. Hassan MA, Yang M, Rasheed A, Yang G, Reynolds M, Xia X, Xiao Y, He Z. A rapid monitoring of NDVI across the wheat growth cycle for grain yield prediction using a multi-spectral UAV platform. Plant Sci. 2019;282:95-103.

80. Li F, Miao Y, Hennig SD, Gnyp ML, Chen X, Jia L, Bareth G. Evaluating hyperspectral vegetation indices for estimating nitrogen concentration of winter wheat at different growth stages. Precision Agric. 2010;11(4):335-57.

81. Baethgen W, Alley M. Optimizing soil and fertilizer nitrogen use by intensively managed winter wheat. I. Crop nitrogen uptake. Agron J. 1989;81(1):116-20.

82. Bedoussac $L$, Justes $E$. The efficiency of a durum wheat-winter pea intercrop to improve yield and wheat grain protein concentration depends on $\mathrm{N}$ availability during early growth. Plant Soil. 2010;330(1):19-35.

83. Olson R, Kurtz L. Crop nitrogen requirements, utilization, and fertilization. Nitrogen in Agricultural Soils. 1982;22:567-604.

84. Meisinger JJ, Schepers J, Raun W. Crop nitrogen requirement and fertilization. Nitrogen in Agricultural Systems. 2008;49:563-612.

85. JU X-t, Zhang C. Nitrogen cycling and environmental impacts in upland agricultural soils in North China: A review. Journal of Integrative Agriculture. 2017;16(12):2848-62.

86. Crippa M, Solazzo E, Guizzardi D, Monforti-Ferrario F, Tubiello F, Leip A. Food systems are responsible for a third of global anthropogenic GHG emissions. Nature Food. 2021;2(3):198-209.

87. Guo J, Jia Y, Chen H, Zhang L, Yang J, Zhang J, Hu X, Ye X, Li Y, Zhou Y. Growth, photosynthesis, and nutrient uptake in wheat are affected by differences in nitrogen levels and forms and potassium supply. Sci Rep. 2019;9(1):1-12.

88. Tegeder M, Masclaux-Daubresse C. Source and sink mechanisms of nitrogen transport and use. New Phytol. 2018;217(1):35-53.

89. Liu R, Lal R. Synthetic apatite nanoparticles as a phosphorus fertilizer for soybean (Glycine max). Sci Rep. 2014;4(1):5686.

90. Yoon HY, Lee JG, Esposti LD, lafisco M, Kim PJ, Shin SG, Jeon J-R, Adamiano A. Synergistic Release of Crop Nutrients and Stimulants from Hydroxyapatite Nanoparticles Functionalized with Humic 
Substances: Toward a Multifunctional Nanofertilizer. ACS Omega. 2020;5(12):6598-610.

91. Tahir ISA, Elbashier EME, Ibrahim MAS, Saad ASI, Abdalla OS. Genetic Gain in Wheat Grain Yield and Nitrogen Use Efficiency at Different Nitrogen Levels in an Irrigated Hot Environment. International Journal of Agronomy. 2020;2020:9024671.

92. Debaeke P, Aussenac T, Fabre JL, Hilaire A, Pujol B, Thuries L. Grain nitrogen content of winter bread wheat (Triticum aestivum L.) as related to crop management and to the previous crop. Eur $\mathrm{J}$ Agron. 1996;5(3):273-86.

93. Lipsett $\mathrm{J}$. The phosphorus content and yield of grain of different wheat varieties in relation to phosphorus deficiency. Aust J Agric Res. 1964;15(1):1-8.

94. Rodríguez D, Pomar M, Goudriaan J. Leaf primordia initiation, leaf emergence and tillering in wheat (Triticum aestivum L.) grown under low-phosphorus conditions. Plant Soil. 1998;202(1):149-57.

95. Samavini R, Sandaruwan C, De Silva M, Priyadarshana G, Kottegoda N, Karunaratne V. Effect of Citric Acid Surface Modification on Solubility of Hydroxyapatite Nanoparticles. J Agric Food Chem. 2018;66(13):3330-7.

96. Gao X, Dai C, Liu W, Liu Y, Shen R, Zheng X, Duan K, Weng J, Qu S. High-scale yield of nano hydroxyapatite through combination of mechanical activation and chemical dispersion. Journal of Materials Science: Materials in Medicine. 2017;28(6):83.

97. Wang H. Hydroxyapatite degradation and biocompatibility. The Ohio State University; 2004.

98. Wang H, Guan S, Wang X, Ren C, Wang L. In vitro degradation and mechanical integrity of Mg- ZnCa alloy coated with Ca-deficient hydroxyapatite by the pulse electrodeposition process. Acta Biomater. 2010;6(5):1743-8.

99. Sumathi S, Gopal B. In vitro degradation of multisubstituted hydroxyapatite and fluorapatite in the physiological condition. J Cryst Growth. 2015;422:36-43.

100. Stoll WR, Neuman WF: The Uptake of Sodium and Potassium lons by Hydrated Hydroxyapatite1. Journal of the American Chemical Society 1956, 78(8):1585-1588.

101. Marschner H. Mineral nutrition of higher plants. 2nd. Edn Academic Pres; 1995.

102. Hepler PK, Wayne RO. Calcium and plant development. Annual Review of Plant Physiology. 1985;36(1):397-439.

103. Wang Z, Hassan MU, Nadeem F, Wu L, Zhang F, Li X. Magnesium Fertilization Improves Crop Yield in Most Production Systems: A Meta-Analysis. Frontiers in Plant Science 2020, 10(1727).

104. Farhat N, Elkhouni A, Zorrig W, Smaoui A, Abdelly C, Rabhi M. Effects of magnesium deficiency on photosynthesis and carbohydrate partitioning. Acta Physiol Plant. 2016;38(6):145.

105. Tiber A, Mukherjee M. Clinical manifestations of zinc deficiency. Am Fam Physician. 1982;26(2):167-72.

106. Palmgren MG, Clemens S, Williams LE, Krämer U, Borg S, Schjørring JK, Sanders D. Zinc biofortification of cereals: problems and solutions. Trends Plant Sci. 2008;13(9):464-73. 
107. Liu D-Y, Liu Y-M, Zhang W, Chen X-P, Zou C-Q. Zinc Uptake, Translocation, and Remobilization in Winter Wheat as Affected by Soil Application of Zn Fertilizer. Frontiers in Plant Science 2019, 10(426).

108. Xiong L, Wang P, Kopittke PM. Tailoring hydroxyapatite nanoparticles to increase their efficiency as phosphorus fertilisers in soils. Geoderma. 2018;323:116-25.

109. Moreno JC, Gómez R, Giraldo L. Removal of Mn, Fe, Ni and Cu lons from Wastewater Using Cow Bone Charcoal. Materials. 2010;3(1):452-66.

110. Le DT, Le TPT, Do HT, Vo HT, Pham NT, Nguyen TT, Cao HT, Nguyen PT, Dinh TMT, Le HV, et al. Fabrication of Porous Hydroxyapatite Granules as an Effective Adsorbent for the Removal of Aqueous $\mathrm{Pb}$ (II) lons. Journal of Chemistry. 2019;2019:8620181.

111. Dwivedi SL, Van Bueren ETL, Ceccarelli S, Grando S, Upadhyaya HD, Ortiz R. Diversifying food systems in the pursuit of sustainable food production and healthy diets. Trends Plant Sci. 2017;22(10):842-56.

112. Wang Y, Zhu Y, Zhang S, Wang Y. What could promote farmers to replace chemical fertilizers with organic fertilizers? J Clean Prod. 2018;199:882-90.

113. Wang G, Lei M, Liu J, He Q, Zhang W. Improving the Stability and Optoelectronic Properties of All Inorganic Less-Pb Perovskites by B-Site Doping for High-Performance Inorganic Perovskite Solar Cells. Solar RRL. 2020;4(12):2000528.

114. Sayahi M, Santos J, El-Feki H, Charvillat C, Bosc F, Karacan I, Milthorpe B, Drouet C. Brushite (Ca, M) HPO4, 2H2O doping with bioactive ions ( $\mathrm{M}=\mathrm{Mg} 2+, \mathrm{Sr} 2+, \mathrm{Zn} 2+, \mathrm{Cu} 2+$, and $\mathrm{Ag}+$ ): a new path to functional biomaterials? Materials Today Chemistry. 2020;16:100230.

115. Favela-Camacho SE, Samaniego-Benítez EJ, Godínez-García A, Avilés-Arellano LM, Pérez-Robles JF. How to decrease the agglomeration of magnetite nanoparticles and increase their stability using surface properties. Colloids Surf A. 2019;574:29-35.

116. Ren X, Zeng G, Tang L, Wang J, Wan J, Liu Y, Yu J, Yi H, Ye S, Deng R. Sorption, transport and biodegradation-an insight into bioavailability of persistent organic pollutants in soil. Science of The Total Environment. 2018;610:1154-63.

117. Kumar R, Prakash K, Cheang P, Khor K. Temperature driven morphological changes of chemically precipitated hydroxyapatite nanoparticles. Langmuir. 2004;20(13):5196-200.

118. Bouyoucos GJ. Hydrometer method improved for making particle size analyses of soils 1 . Agron J. 1962;54(5):464-5.

119. Subbaiah B. A rapid procedure for estimation of available nitrogen in soil. Curr Sci. 1956;25:259-60.

120. Olsen SR. Estimation of available phosphorus in soils by extraction with sodium bicarbonate. US Department of Agriculture; 1954.

121. Hanway J, Heidel H. Soil analysis methods as used in lowa state college soil testing laboratory. lowa Agriculture. 1952;57:1-31. 
122. Walkley A, Black IA. An examination of the Degtjareff method for determining soil organic matter, and a proposed modification of the chromic acid titration method. Soil Sci. 1934;37(1):29-38.

123. Srivastava AK, Singh S. Citrus decline: Soil fertility and plant nutrition. J Plant Nutr. 2009;32(2):197245.

124. Lindsay WL, Norvell WA. Development of a DTPA soil test for zinc, iron, manganese, and copper. Soil Science Society of America journal. 1978;42(3):421-8.

125. Greenan N, Mulvaney R, Sims G. A microscale method for colorimetric determination of urea in soil extracts. Commun Soil Sci Plant Anal. 1995;26(15-16):2519-29.

126. Marsh WH, Fingerhut B, Miller H. Automated and manual direct methods for the determination of blood urea. Clin Chem. 1965;11(6):624-7.

127. Nelson DW, Sommers LE. Total Nitrogen Analysis of Soil and Plant Tissues. Journal of Association of Official Analytical Chemists. 2020;63(4):770-8.

128. Bremner J. Determination of nitrogen in soil by the Kjeldahl method. The Journal of Agricultural Science. 1960;55(1):11-33.

129. Hanson W. The photometric determination of phosphorus in fertilizers using the phosphovanadomolybdate complex. J Sci Food Agric. 1950;1(6):172-3.

130. Severenghaus J, Ferrebee J. Calcium determination by flame photometry; methods for serum, urine, and other fluids. J Biol Chem. 1950;187:621-30.

131. Brealey $L$. The determination of potassium in fertilisers by flame photometry. Analyst. 1951;76(903):340-3.

132. Padhye V. A rapid method for the determination of calcium and magnesium in plant material by titration with disodium ethylenediaminetetra-acetate. Analyst. 1957;82(978):634-8.

133. ZOOK EG, GREENE FE, Morris E. Nutrient composition of selected wheats and wheat products. 6 . Distribution of manganese, copper, nickel, zinc, magnesium, lead, tin, cadmium, chromium, and selenium as determined by atomic absorption spectroscopy and colorimetry. Cereal Chem. 1970;47:720-31.

134. Meret S, Henkin R. Simultaneous direct estimation by atomic absorption spectrophotometry of copper and zinc in serum, urine, and cerebrospinal fluid. Clin Chem. 1971;17(5):369-73.

135. Compton SJ, Jones CG. Mechanism of dye response and interference in the Bradford protein assay. Anal Biochem. 1985;151(2):369-74.

136. Zilversmit D, Davis AK. Microdetermination of plasma phospholipids by trichloroacetic acid precipitation. The Journal of Laboratory Clinical Medicine. 1950;35(1):155-60.

137. Bates LS, Waldren RP, Teare I. Rapid determination of free proline for water-stress studies. Plant Soil. 1973;39(1):205-7.

\section{Figures}




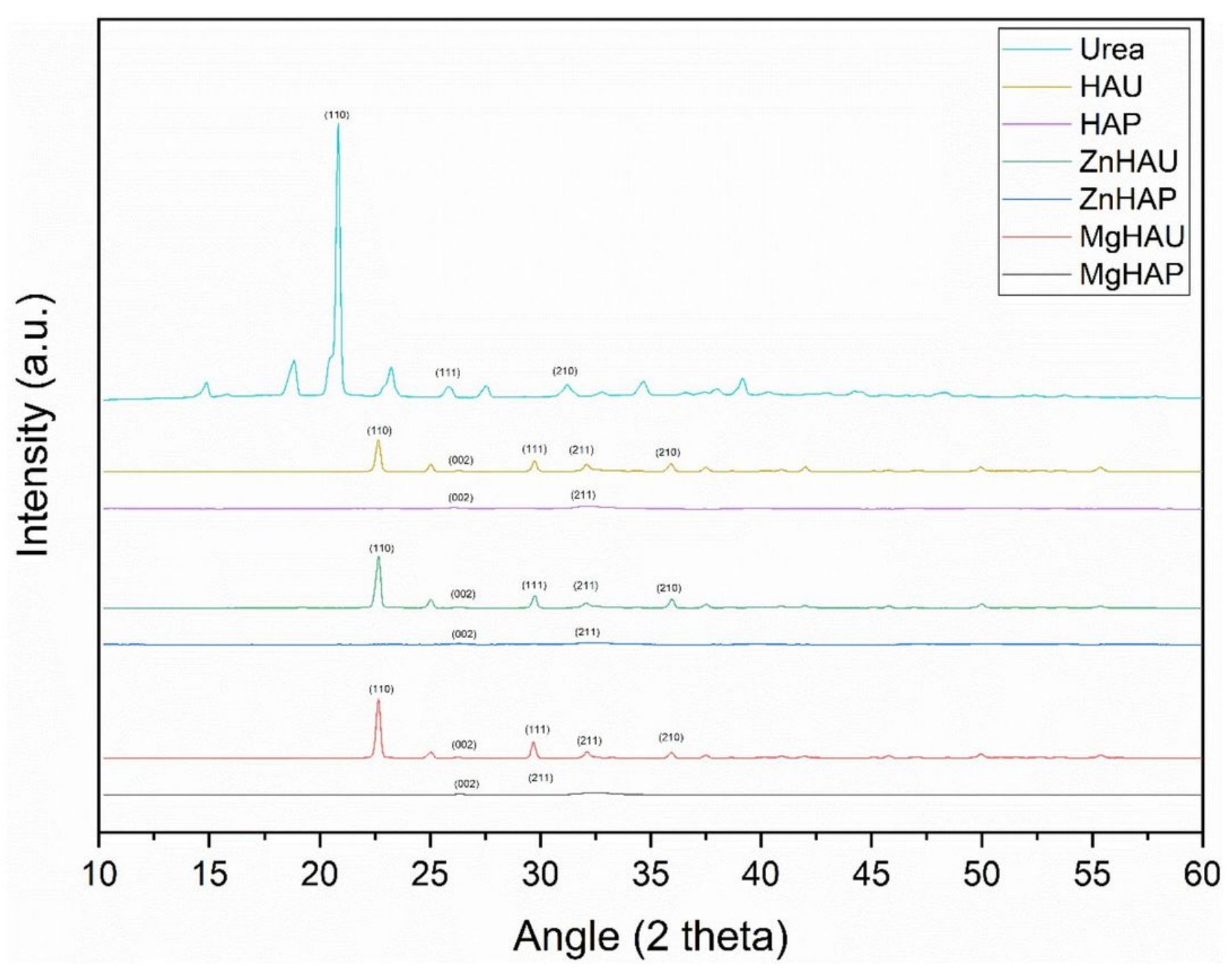

Figure 1

Powder X-ray diffraction (PXRD) analysis of the synthesized nanohybrids. XRD patterns (Up to down) of the Urea, HAU, HAP, ZnHAU, ZnHAP, MgHAU, and MgHAP. 


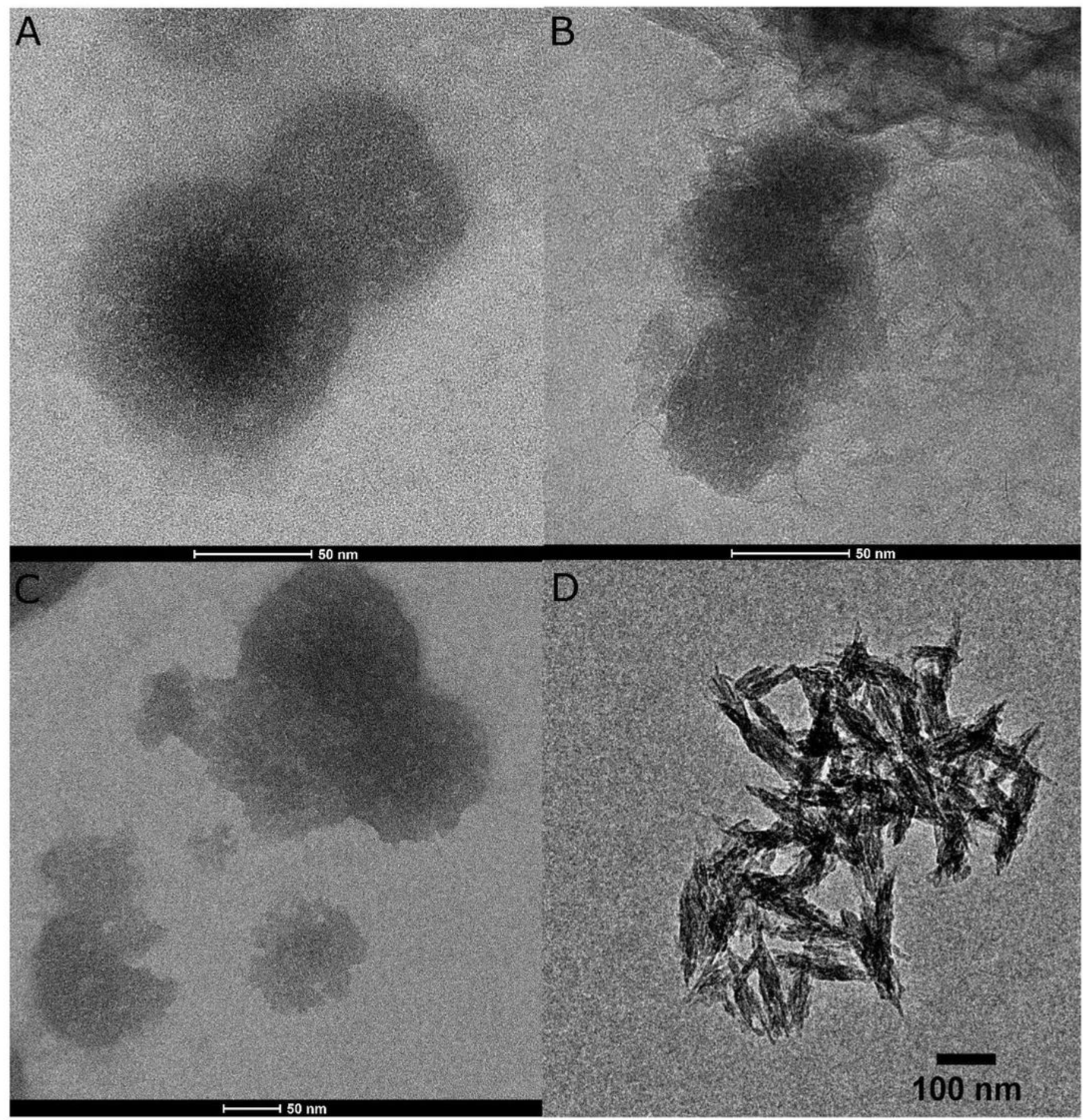

\section{Figure 2}

Cryo-transmission electron microscopy (cryo-TEM) images of the synthesized nanoparticles. A) Hydroxyapatite-urea (HAU), B) Magnesium doped hydroxyapatite-urea (MgHAU), and C) Zinc doped hydroxyapatite-urea (ZnHAU), D) Hydroxyapatite (HAP). 


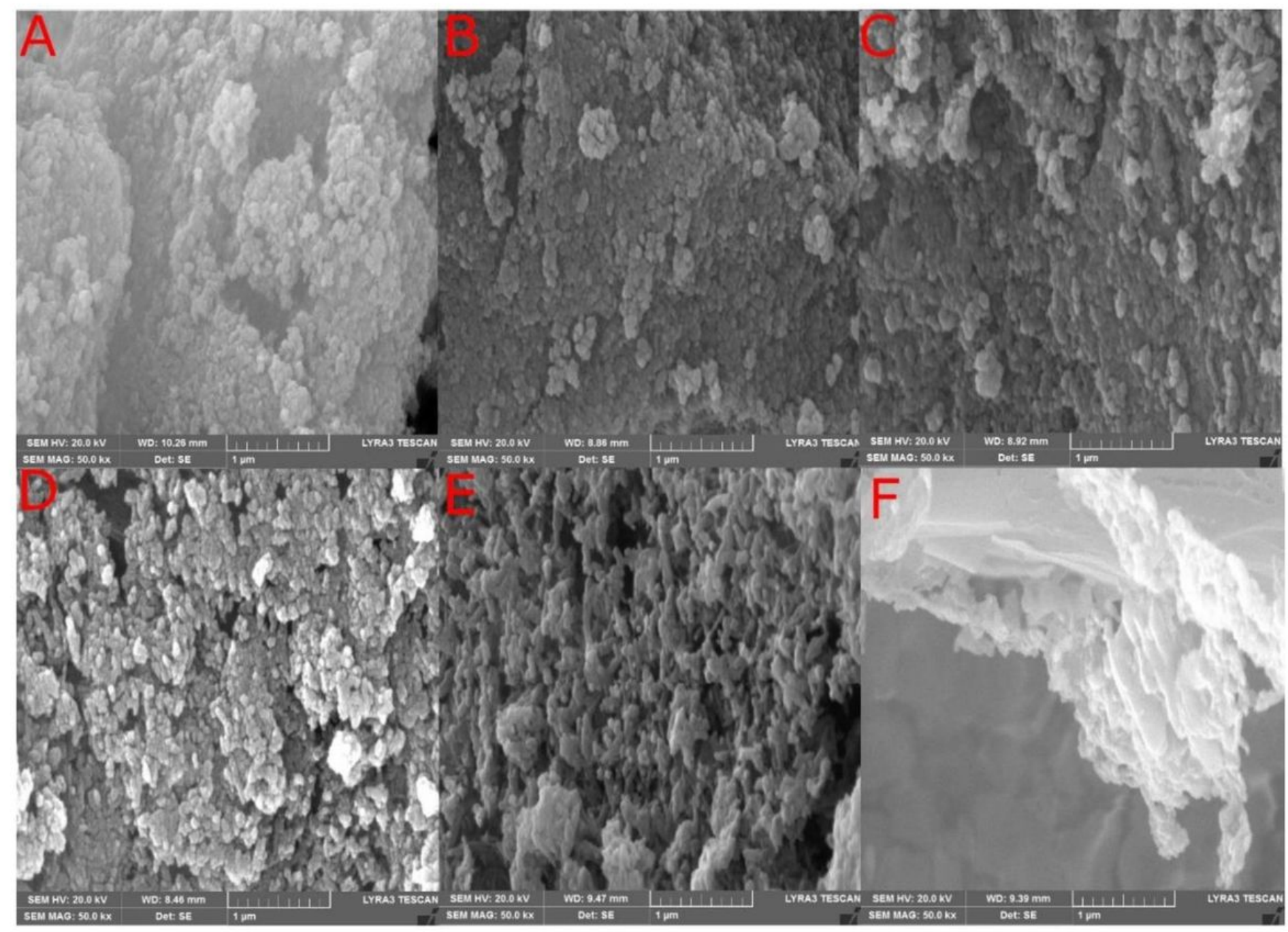

\section{Figure 3}

Scanning electron microscopy (SEM) images of the synthesized nanoparticles. A) Hydroxyapatite (HAP), B) Magnesium doped hydroxyapatite (MgHAP), C) Zinc doped hydroxyapatite (ZnHAP), D) Hydroxyapatite-urea (HAU), E) Magnesium doped hydroxyapatite-urea (MgHAU), and F) Zinc doped hydroxyapatite-urea (ZnHAU). 

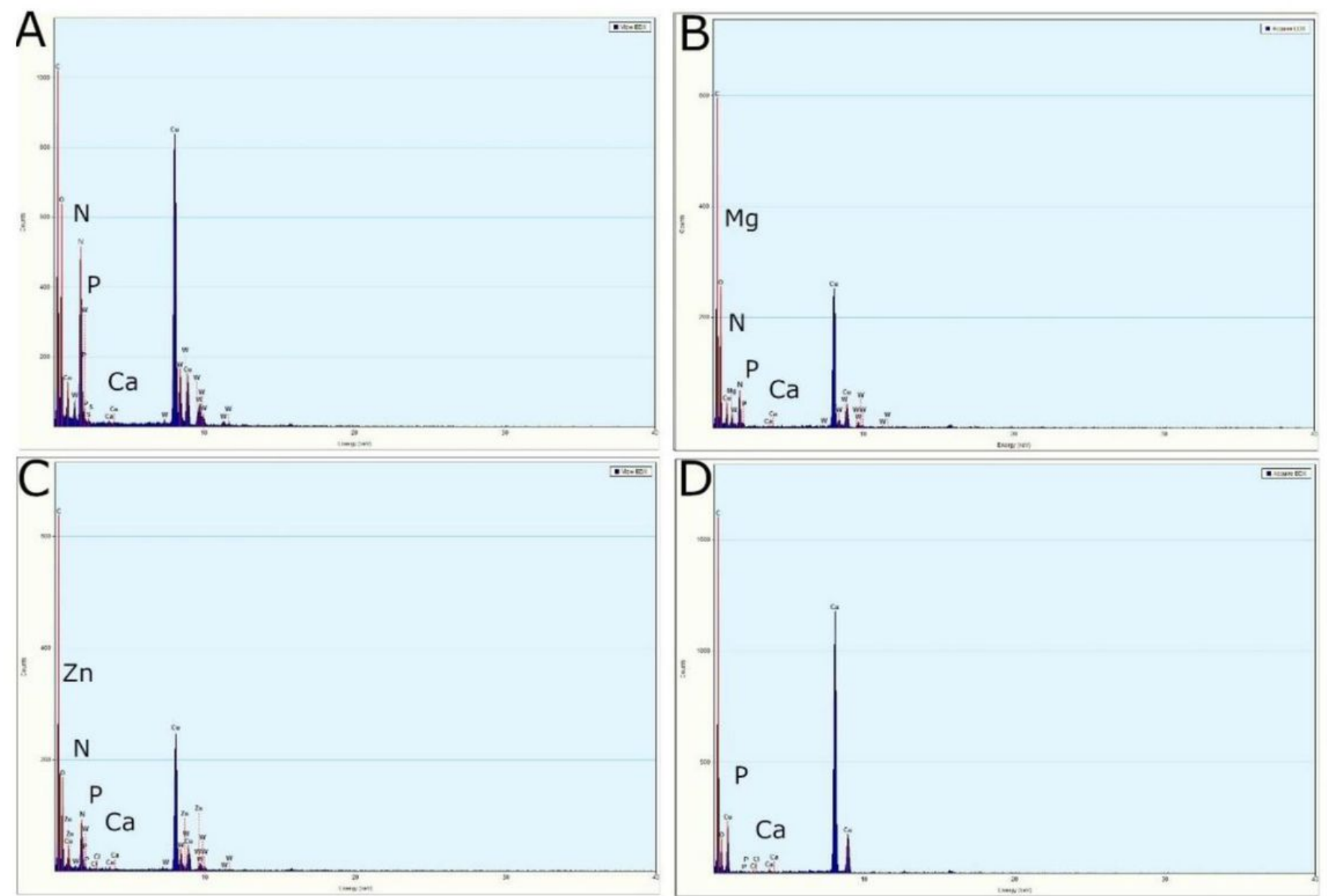

Figure 4

Energy-dispersive X-ray analysis of the nanohybrids. EDX analysis of the A) HAU, B) MgHAU, C) ZnHAU, and D) HAP. The analysis confirms the presence of calcium, nitrogen, and phosphorus in all the synthesized hydroxyapatite nanohybrids (except HAP), while zinc and magnesium doped nanohybrids were exclusively observed with additional zinc and magnesium. 

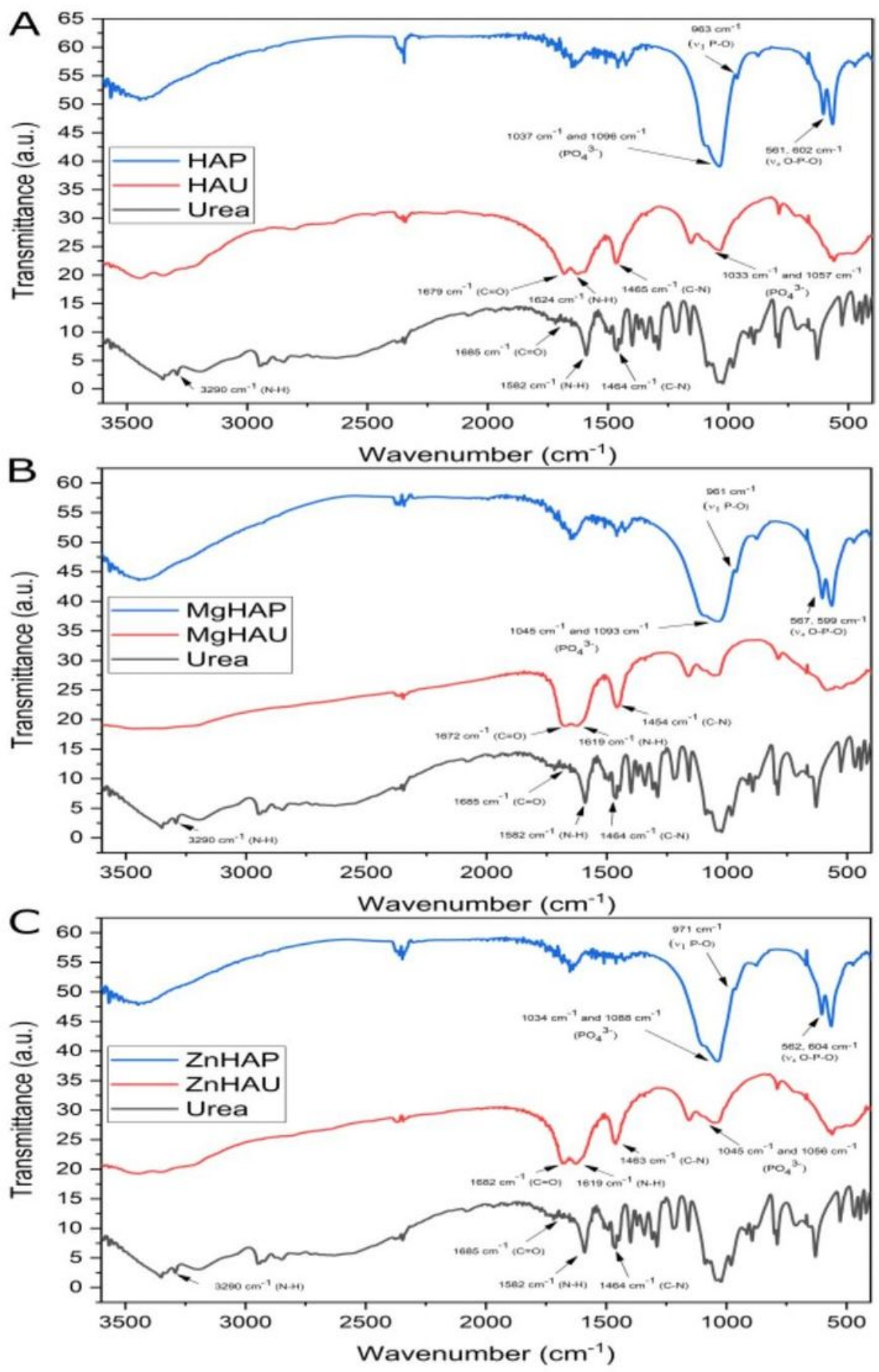

\section{Figure 5}

Fourier Transform Infrared (FTIR) spectrum of the synthesized nanohybrids. A) HAP, HAU, and urea) B) MgHAP, MgHAU, and urea C) ZnHAP, ZnHAU, and urea. 


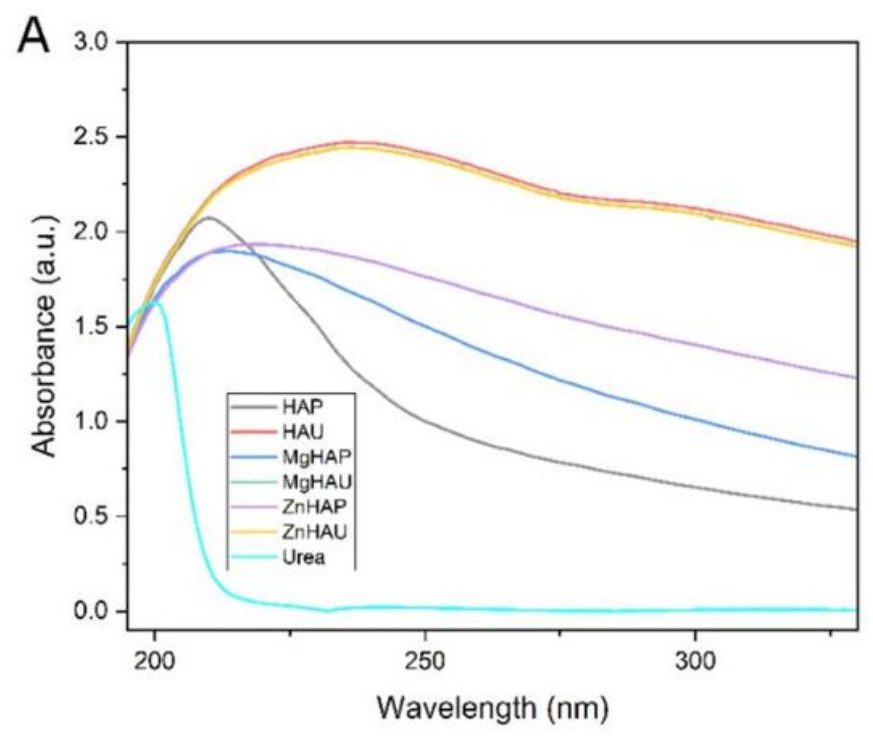

B

\begin{tabular}{lll}
\hline Nanoparticles & $\begin{array}{l}\text { Hydrodynamic } \\
\text { diameter } \\
(\mathrm{nm})\end{array}$ & $\begin{array}{l}\text { Zeta Potential } \\
(\mathrm{mV})\end{array}$ \\
\hline Hydroxyapatite & $406.6 \pm 66.9$ & $20.2 \mathrm{mV}$ \\
\hline Magnesium doped hydroxyapatite & $182.3 \pm 14.4$ & $24.9 \mathrm{mV}$ \\
\hline Zinc doped hydroxyapatite & $246.2 \pm 31.1$ & $10.8 \mathrm{mV}$ \\
\hline Hydroxyapatite-urea & $721.8 \pm 83.7$ & $-5.1 \mathrm{mV}$ \\
\hline Magnesium doped hydroxyapatite-urea & $382.1 \pm 52.2$ & $-14.8 \mathrm{mV}$ \\
\hline Zinc doped hydroxyapatite-urea & $472.9 \pm 45.9$ & $-9.3 \mathrm{mV}$ \\
\hline
\end{tabular}

\section{Figure 6}

UV-visible spectrum, DLS, and Zeta potential of the synthesized nanohybrids. A) UV-visible spectrum of the synthesized urea-nanohybrids, bare nanoparticles, and urea. B) Hydrodynamic diameter and Zeta potential measurements of synthesized urea-nanohybrids and bare nanoparticles. 


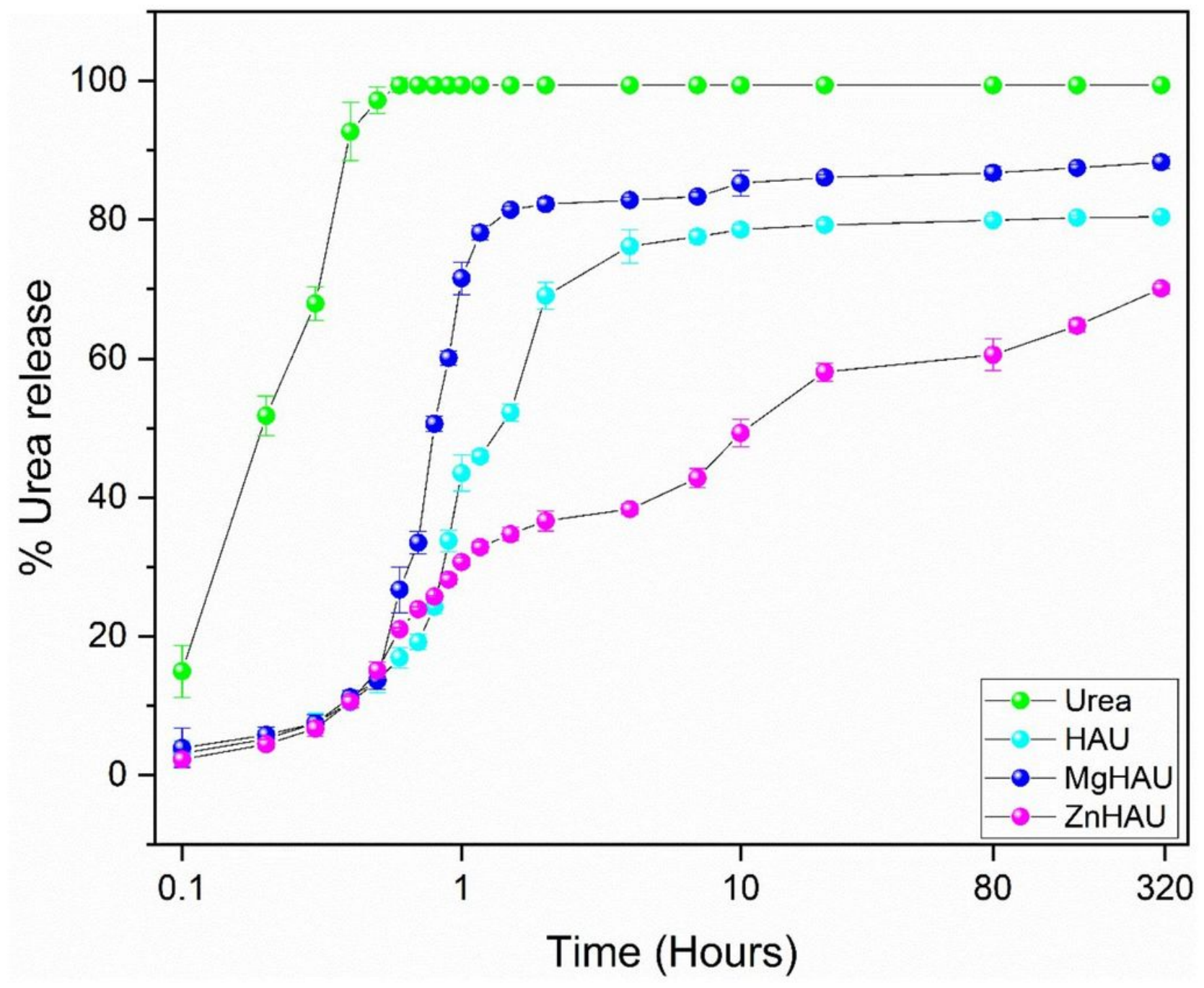

Figure 7

Comparative analysis of the urea release from nanohybrids (HAU, MgHAU, ZnHAU) and urea granules incubated with water in the soil matrix for up to 320 hours. 

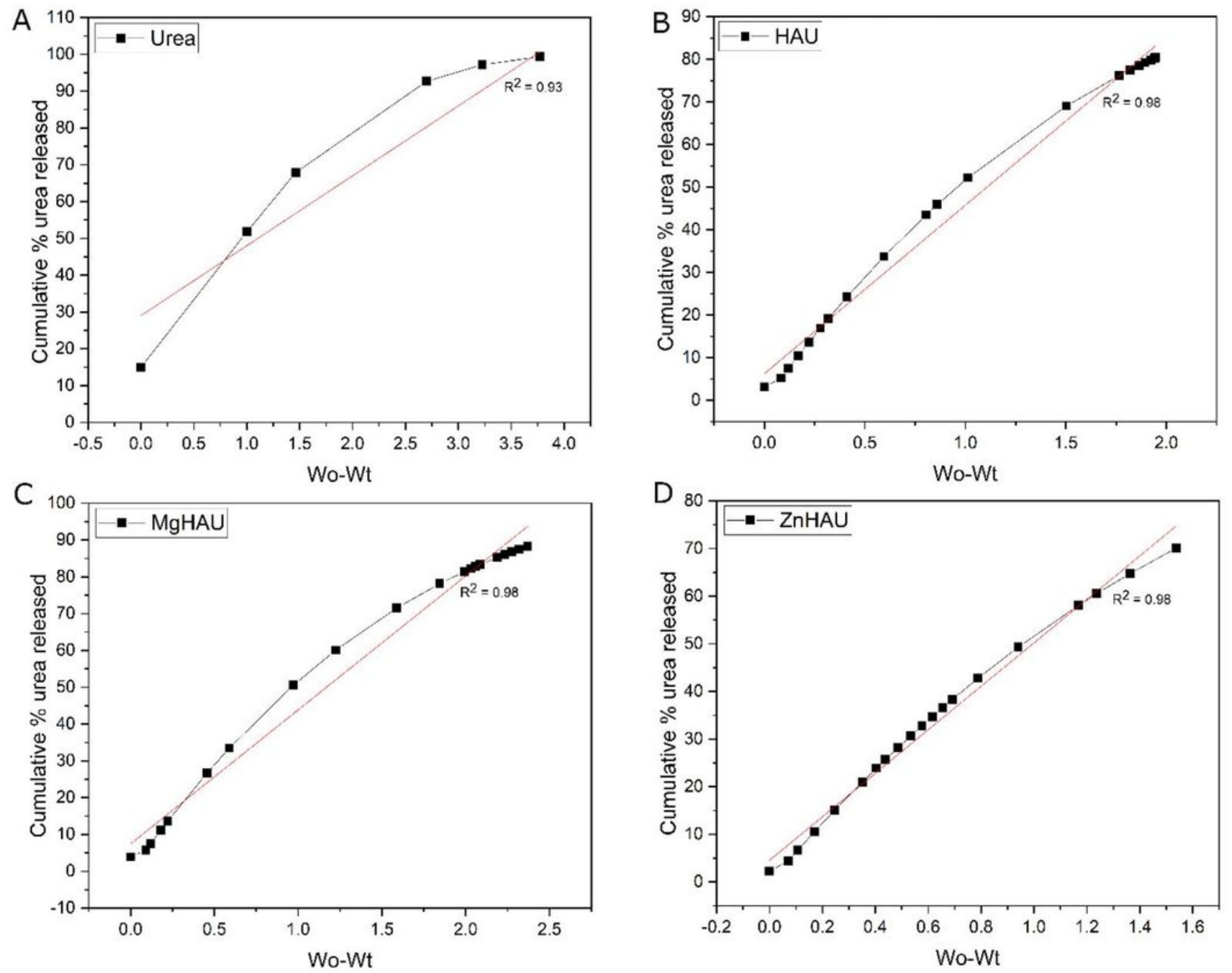

Figure 8

Comparative urea release kinetics study. A) urea, B) hydroxyapatite-urea (HAU), C) magnesium-doped hydroxyapatite-urea (MgHAU), D) zinc-doped hydroxyapatite-urea (ZnHAU) in the water environment using the Hixson-Crowell model equation. 

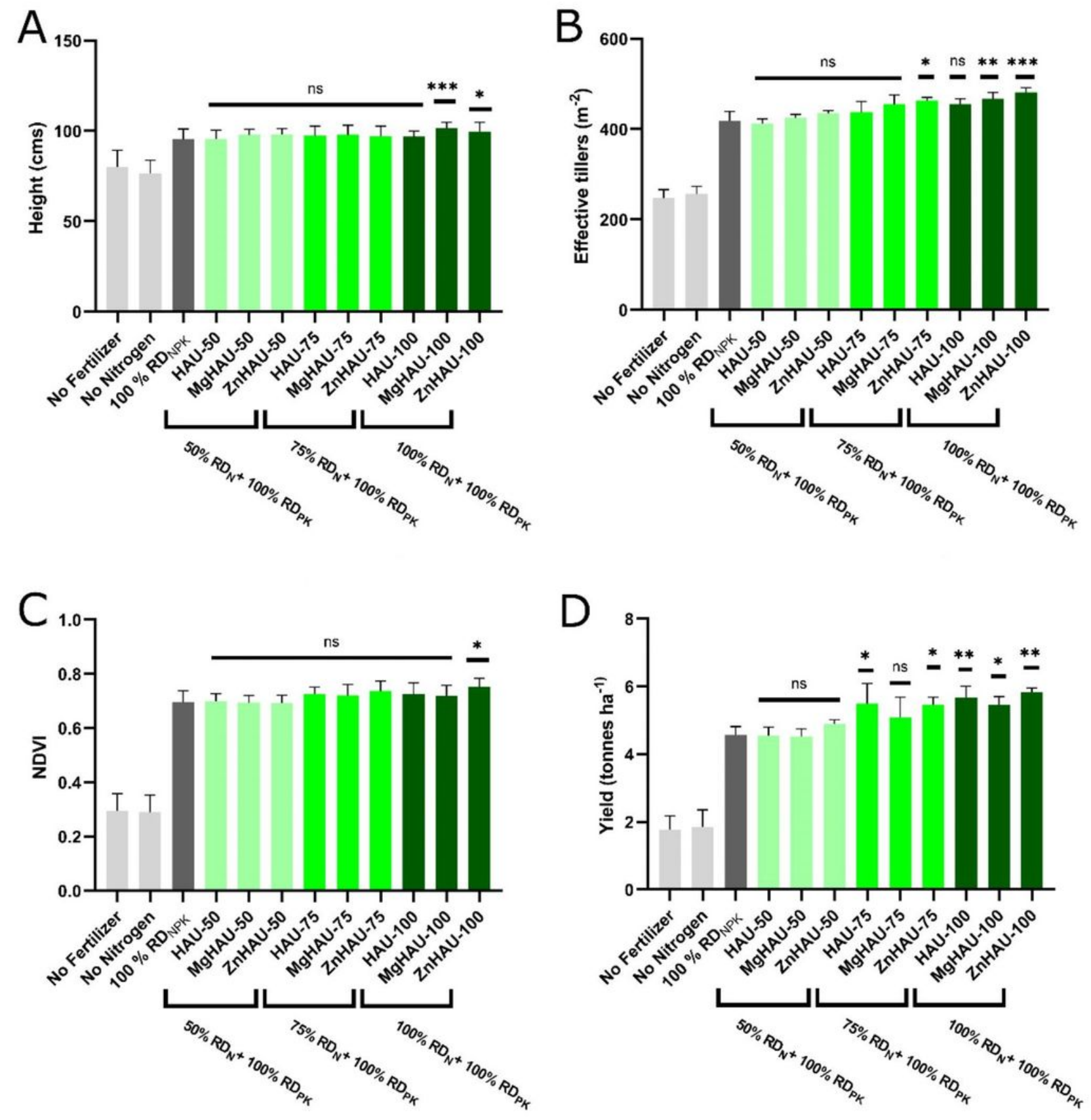

Figure 9

Wheat growth and yield parameters: plant height, effective tillers, spike length, and spike count. A) Plant height, B) Effective tillers, C) NDVI level, and D) Straw yield parameters of the wheat crop treated with $50 \%, 75 \%$, and $100 \%$ nitrogen doses as nanohybrids, full dose of nitrogen as urea fertilizer (control or $100 \%$ RDNPK), No Nitrogen, and without fertilizer (No Fertilizer). All the nanohybrid treatments are compared with the control or $100 \%$ RDNPK treatment. The values are provided as mean \pm standard deviation and statistical significance was calculated by one-way ANOVA with Dunnett's multiple

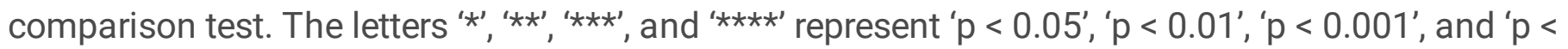
0.0001 ', respectively and 'ns' represents 'not significant'. 

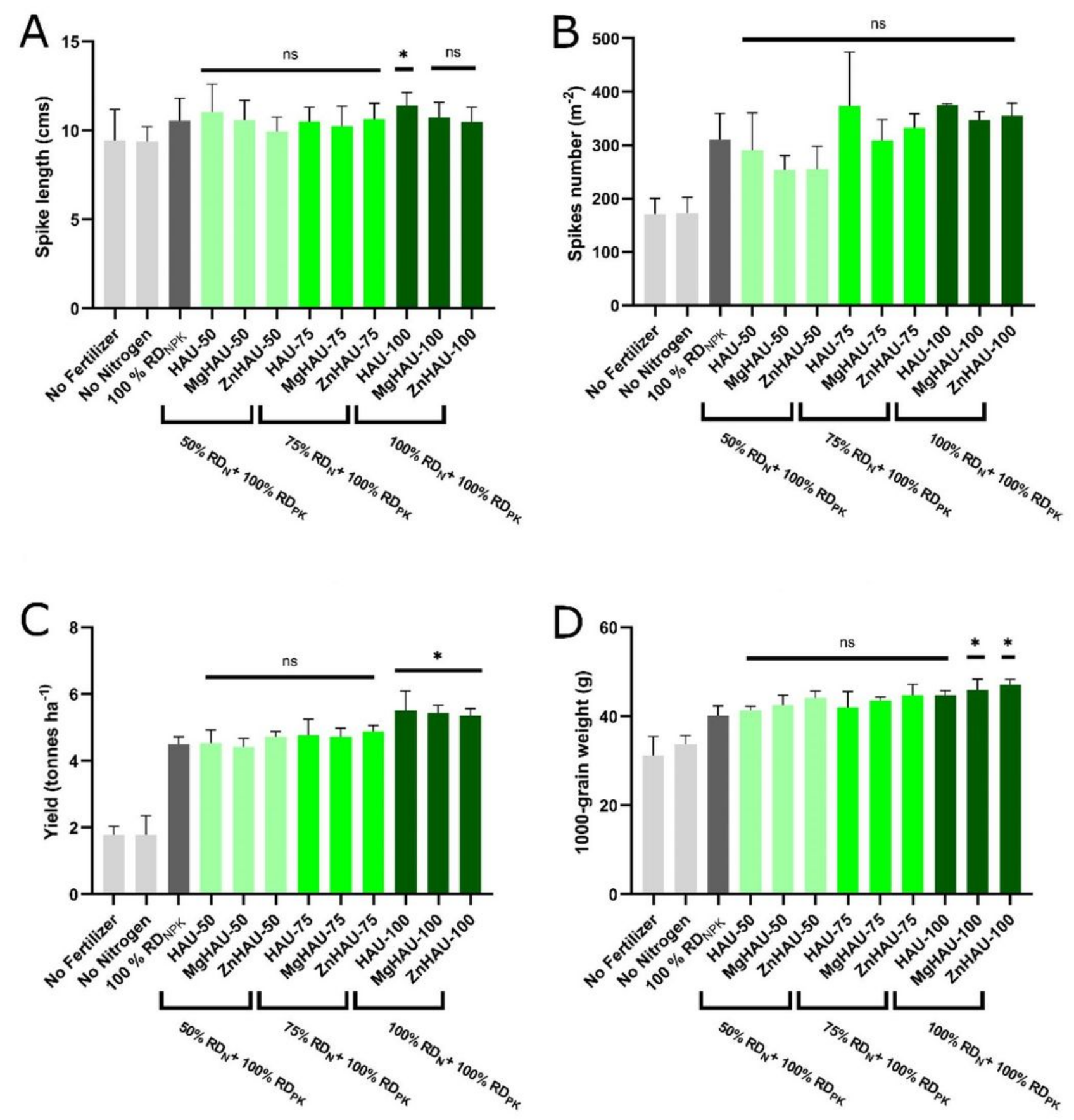

Figure 10

Wheat growth and yield parameters: spike length, spike count, yield, and thousand kernel/grain weight. A) Spike length, B) Spike count, C) Grain yield, and H) Thousand kernel/grain weight parameters of the wheat crop treated with $50 \%, 75 \%$, and $100 \%$ nitrogen doses as nanohybrids, full dose of nitrogen as urea fertilizer (control or $100 \%$ RDNPK), No Nitrogen, and without fertilizer (No Fertilizer). All the nanohybrid treatments are compared with the control or $100 \%$ RDNPK treatment. The values are provided as mean \pm standard deviation and statistical significance was calculated by one-way ANOVA with Dunnett's multiple 


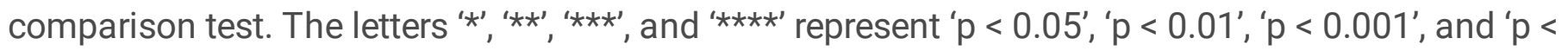
0.0001 ', respectively and 'ns' represents 'not significant'.

\section{Wheat leaf nitrogen}

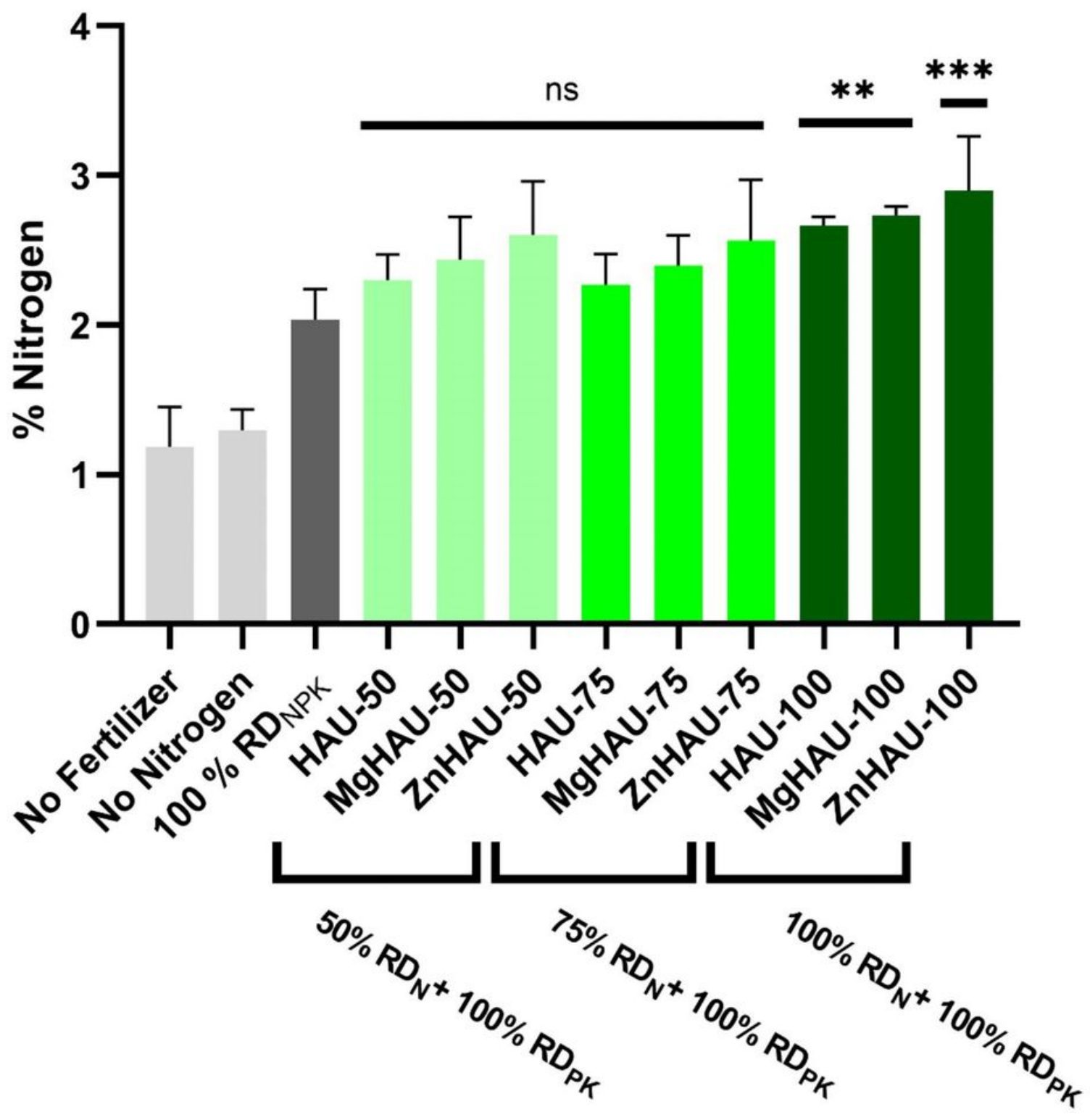

Figure 11

Nitrogen uptake in nanohybrids treated wheat leaf tissues. Leaf nitrogen content of the 40 days wheat plants treated with $50 \%, 75 \%$, and $100 \%$ nitrogen doses as nanohybrids, full dose of nitrogen as urea fertilizer (control or $100 \%$ RDNPK), No Nitrogen, and without fertilizer (No Fertilizer). All the nanohybrid treatments are compared with the control or $100 \%$ RDNPK treatment. The values are provided as mean \pm 
standard deviation and statistical significance was calculated by one-way ANOVA with Dunnett's multiple

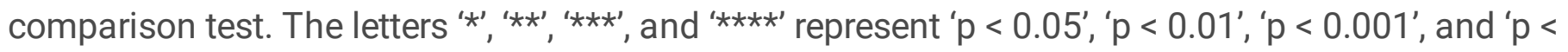
0.0001 ', respectively and 'ns' represents 'not significant'.
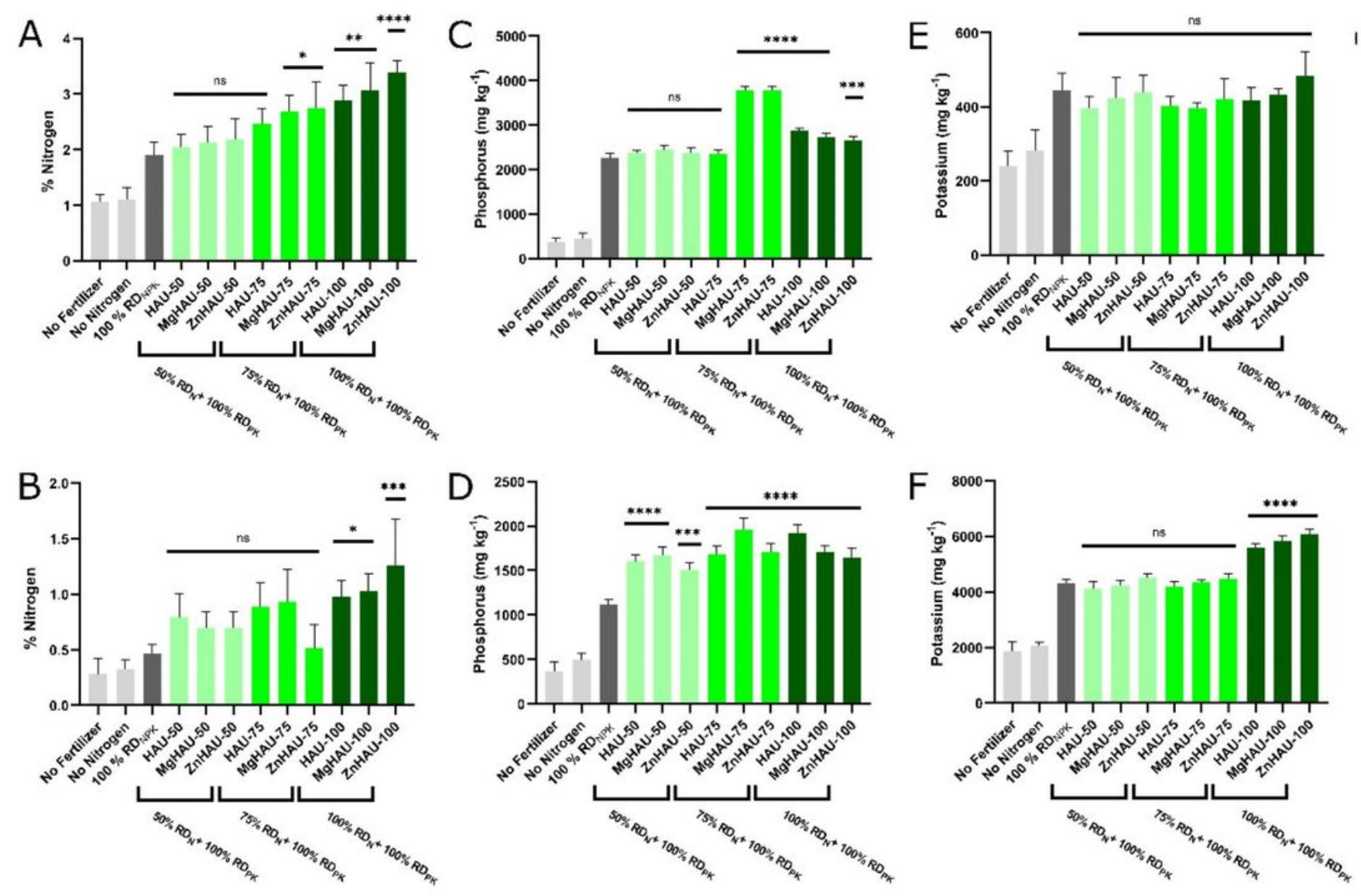

Figure 12

Macronutrients (nitrogen, phosphorus, potassium) accumulation in tissues of nanohybrids treated wheat crop. A) grain nitrogen, B) stem nitrogen, C) grain phosphorus, D) stem phosphorus, E) grain potassium, and F) stem potassium levels were estimated in the wheat crop after harvesting of the wheat crop treated with $50 \%, 75 \%$, and $100 \%$ nitrogen doses as nanohybrids, full dose of nitrogen as urea fertilizer (control or $100 \%$ RDNPK), No Nitrogen, and without fertilizer (No Fertilizer). All the nanohybrid treatments are compared with the control or $100 \%$ RDNPK treatment. The values are provided as mean \pm standard deviation and statistical significance was calculated by one-way ANOVA with Dunnett's multiple

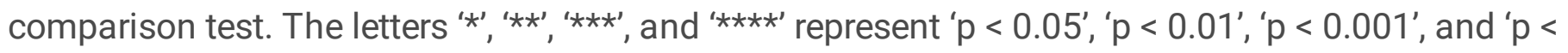
0.0001 ', respectively and 'ns' represents 'not significant'. 

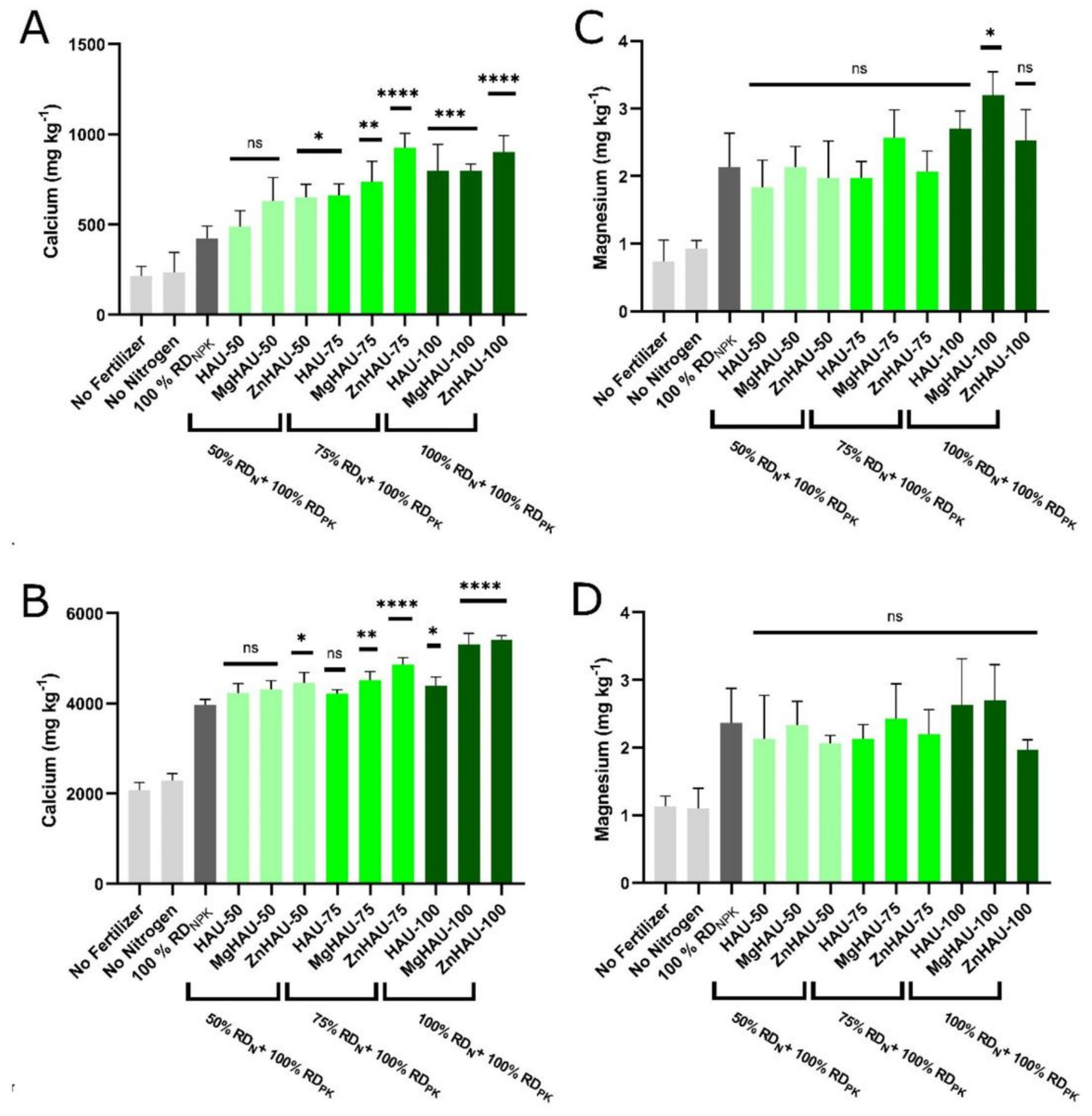

Figure 13

Macronutrients (calcium and magnesium) accumulation in tissues of nanohybrids treated wheat crop. A) grain calcium, B) stem calcium, C) grain magnesium, and D) stem magnesium levels were estimated in the wheat crop after harvesting of the wheat crop treated with $50 \%, 75 \%$, and $100 \%$ nitrogen doses as nanohybrids, full dose of nitrogen as urea fertilizer (control or $100 \%$ RDNPK), No Nitrogen, and without fertilizer (No Fertilizer). All the nanohybrid treatments are compared with the control or $100 \%$ RDNPK 

represent ' $p<0.05$ ', ' $p<0.01$ ', ' $p<0.001$ ', and ' $p<0.0001$ ', respectively and 'ns' represents 'not significant'.
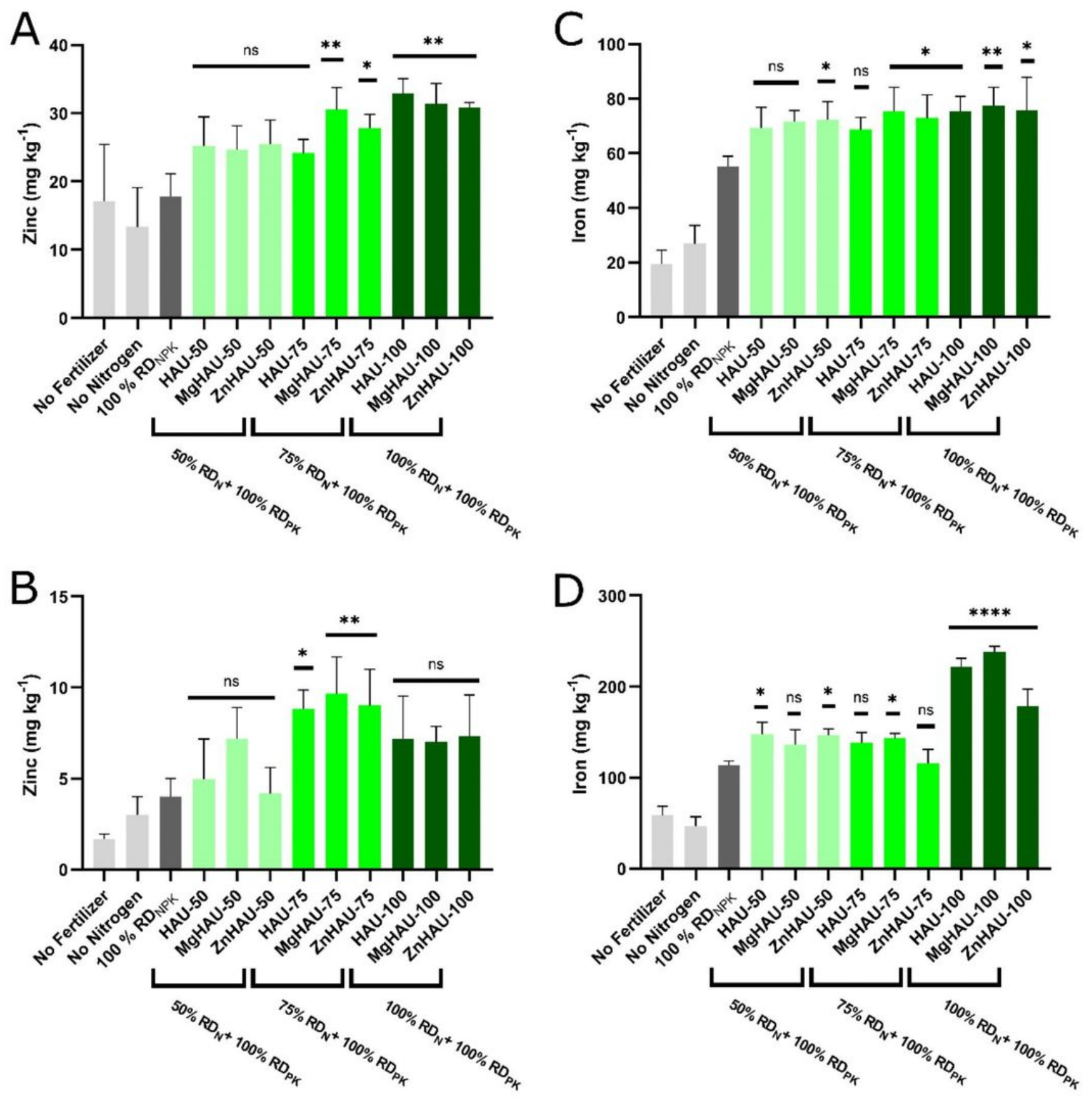

\section{Figure 14}

Micronutrients (Zinc and iron) accumulation in tissues of the nanohybrids treated wheat crop. A) grain zinc, B) stem zinc, C) grain iron, and D) stem iron levels were estimated in the wheat crop after harvesting of the wheat crop treated with $50 \%, 75 \%$, and $100 \%$ nitrogen doses as nanohybrids, full dose of nitrogen as urea fertilizer (control or 100\% RDNPK), No Nitrogen, and without fertilizer (No Fertilizer). All the 
nanohybrid treatments are compared with the control or $100 \%$ RDNPK treatment. The values are provided as mean \pm standard deviation and statistical significance was calculated by one-way ANOVA with

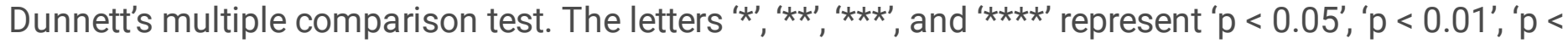
0.001 ', and ' $p<0.0001$ ', respectively and 'ns' represents 'not significant'.

A
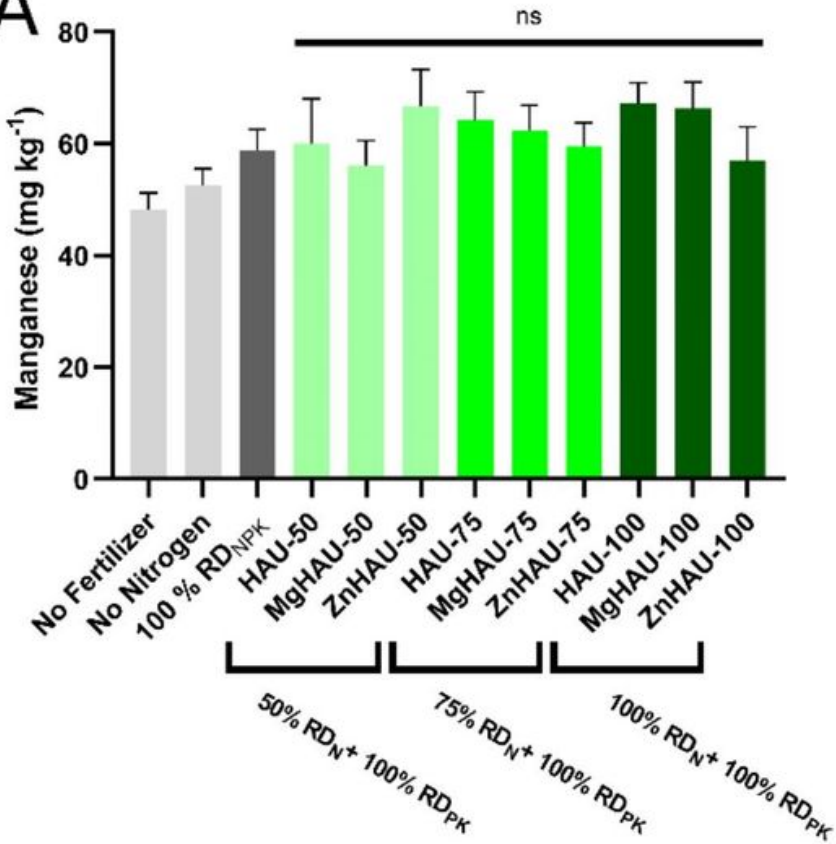

$B$
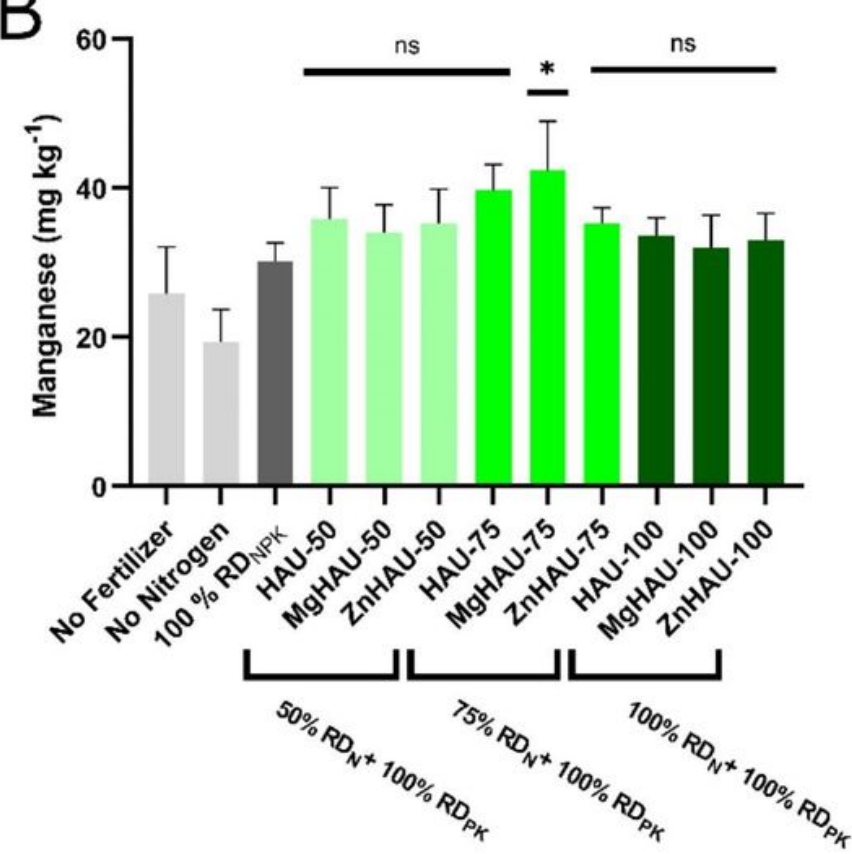
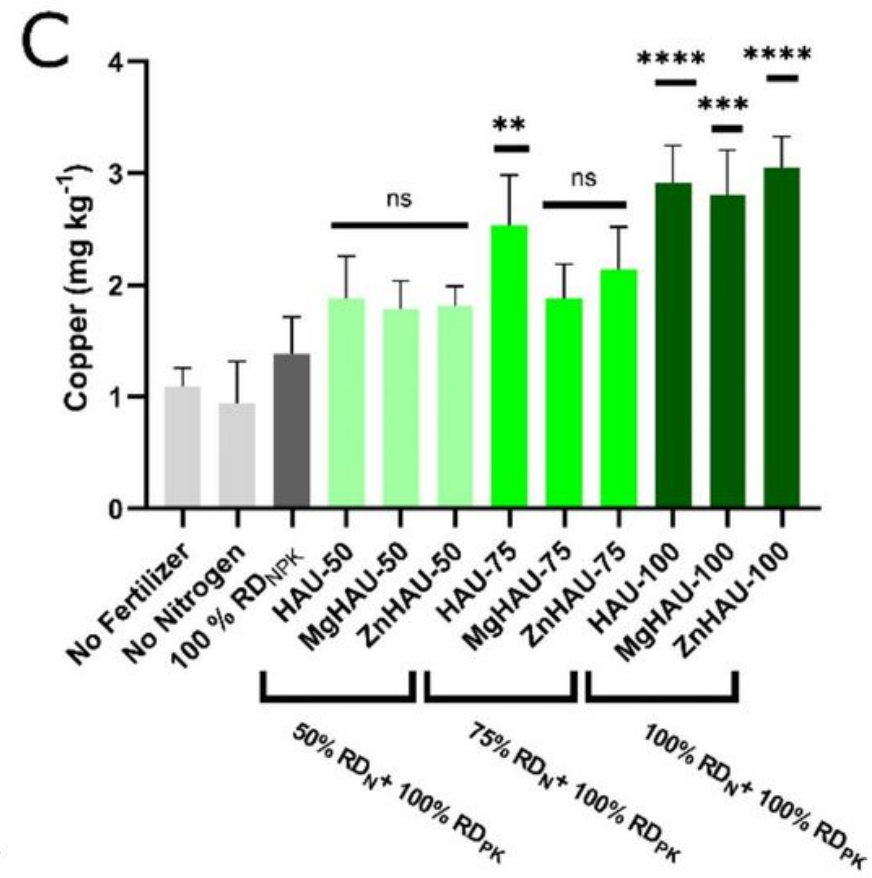

$\mathrm{D}$
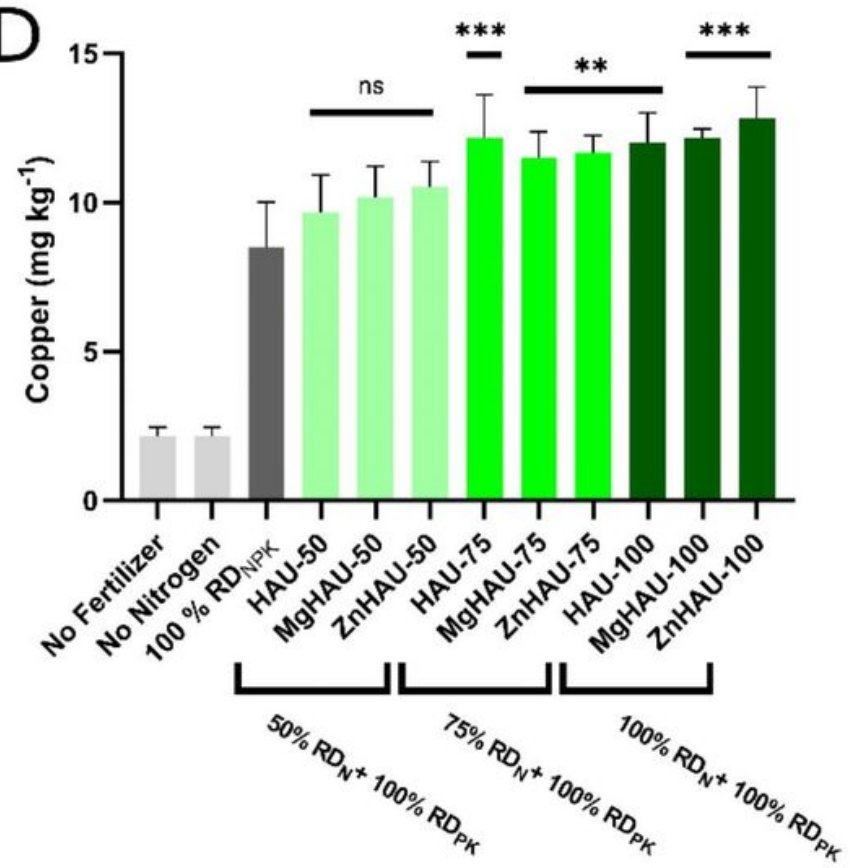

Figure 15

Micronutrients (manganese, and copper) accumulation in tissues of the nanohybrids treated wheat crop. A) grain manganese, B) stem manganese, C) grain copper, and D) stem copper levels were estimated in 
the wheat crop after harvesting of the wheat crop treated with $50 \%, 75 \%$, and $100 \%$ nitrogen doses as nanohybrids, full dose of nitrogen as urea fertilizer (control or 100\% RDNPK), No Nitrogen and without fertilizer (No Fertilizer). All the nanohybrid treatments are compared with the control or $100 \%$ RDNPK treatment. The values are provided as mean \pm standard deviation and statistical significance was

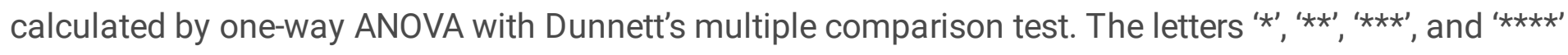
represent ' $p<0.05$ ', 'p $<0.01$ ', 'p $<0.001$ ', and ' $p<0.0001$ ', respectively and 'ns' represents 'not significant'.

\section{Supplementary Files}

This is a list of supplementary files associated with this preprint. Click to download.

- GA1.png 